\title{
Vitamin D Deficiency in India: Prevalence, Causalities and Interventions
}

\author{
Ritu G ${ }^{1}$ and Ajay Gupta ${ }^{1,2, *}$ \\ 1 Charak Foundation, P.O. Box 3547, Cerritos, CA 90703, USA \\ 2 Rockwell Medical Inc., 30142 S. Wixom Road, Wixom, MI 48393, USA \\ * Author to whom correspondence should be addressed; E-Mail: agupta@rockwellmed.com; \\ Tel.: +1-562-809-8899; Fax: +1-702-974-1001.
}

Received: 16 November 2013; in revised form: 28 January 2014 / Accepted: 28 January 2014 / Published: 21 February 2014

\begin{abstract}
Vitamin D deficiency prevails in epidemic proportions all over the Indian subcontinent, with a prevalence of $70 \%-100 \%$ in the general population. In India, widely consumed food items such as dairy products are rarely fortified with vitamin D. Indian socioreligious and cultural practices do not facilitate adequate sun exposure, thereby negating potential benefits of plentiful sunshine. Consequently, subclinical vitamin D deficiency is highly prevalent in both urban and rural settings, and across all socioeconomic and geographic strata. Vitamin D deficiency is likely to play an important role in the very high prevalence of rickets, osteoporosis, cardiovascular diseases, diabetes, cancer and infections such as tuberculosis in India. Fortification of staple foods with vitamin $\mathrm{D}$ is the most viable population based strategy to achieve vitamin D sufficiency. Unfortunately, even in advanced countries like USA and Canada, food fortification strategies with vitamin D have been only partially effective and have largely failed to attain vitamin D sufficiency. This article reviews the status of vitamin D nutrition in the Indian subcontinent and also the underlying causes for this epidemic. Implementation of population based educational and interventional strategies to combat this scourge require recognition of vitamin D deficiency as a public health problem by the governing bodies so that healthcare funds can be allocated appropriately.
\end{abstract}

Keywords: vitamin D; vitamin D deficiency; 25-hydroxyvitamin D; India; Indian subcontinent; healthy individuals; fortification strategies; supplementation; sun exposure; osteoporosis; fractures 


\section{Introduction}

Vitamin D deficiency is pandemic, yet it is the most under-diagnosed and under-treated nutritional deficiency in the world [1-3]. Vitamin D deficiency is widespread in individuals irrespective of their age, gender, race and geography. Vitamin D is photosynthesized in the skin on exposure to UVB rays. Sun exposure alone ought to suffice for vitamin D sufficiency. However, vitamin D deficiency is widely prevalent despite plentiful sunshine even in tropical countries like India.

Vitamin D deficiency has a bearing not only on skeletal but also on extraskeletal diseases. Owing to its multifarious implications on health, the epidemic of vitamin D deficiency in India is likely to significantly contribute to the enormous burden on the healthcare system of India. Cultural and social taboos often dictate lifestyle patterns such as clothing - that may limit sun exposure and vegetarianism - which certainly limits vitamin D rich dietary options. Most Indians are vegetarians. The socioeconomically backward people constitute a large percentage of the population in India. The underprivileged generally suffer from overall poor nutrition. Vitamin D rich dietary sources are limited and unaffordable to most Indians. Vitamin D supplements are available, but most Indians are not aware that they need additional vitamin D. Additionally, the cost of these supplements is essentially prohibitive to the majority. Fortification of staple foods with vitamin $\mathrm{D}$ may prove to be a more viable solution towards attaining vitamin D sufficiency in India.

There are scores of research papers in the literature reporting poor vitamin D status from all over India and some from other countries of the Indian subcontinent too. These research papers have been included in this review. Many of these studies measured serum 25-hydroxyvitamin D levels in ostensibly healthy subjects. Biochemical evidences of suboptimal bone health are elevated alkaline phosphatase (ALP) and elevated PTH levels (secondary hyperparathyroidism or SHPT). These were often reported in research papers, especially with respect to their correlation with vitamin D status. However, the most accurate and convincing measure of bone mineral density (BMD) is DEXA (Dual Energy X-ray Absorptiometry). Research articles reporting BMD, as measured by DEXA, in the context of vitamin D status of ostensibly healthy individuals, are few. BMD data, as they correlated with the vitamin D status in ostensibly healthy Indians is compiled. A few articles also reported results of interventions studies such as vitamin D supplementation and vitamin D fortified foods.

The aim of the paper is to impress upon the practicing physicians in India about the gravity of the vitamin D deficiency problem throughout India, so that they may take necessary caution and care in the diagnosis and treatment of vitamin D deficiency. Additionally, this article may also serve to make the case to the Health ministry, and the Food and Nutrition Board in India for population based strategy of fortification of staple foods with vitamin D. This paper provides a comprehensive picture of the vitamin D status of ostensibly healthy Indians, countrywide. The most reliable marker of vitamin D status is the serum concentration of $25(\mathrm{OH}) \mathrm{D}$. In the publications, investigators reported their data on $25(\mathrm{OH}) \mathrm{D}$ levels either as $\mathrm{nM}$ (nanomoles per liter) or $\mathrm{ng} / \mathrm{mL}$. To simplify information and for the ease of comparison, in this review all the data on $25(\mathrm{OH}) \mathrm{D}$ levels are presented in a single concentration unit for serum 25(OH)D levels - ng/mL. Most investigators have used different cut-off levels to define vitamin D deficiency, insufficiency and sufficiency levels. While some may have done so due to preference perhaps, other investigators defined their own cut-off levels as determined by the linear regression between 25(OH)D levels and PTH levels. Therefore, to further facilitate comparison, in this 
review vitamin D deficiency is defined as $25(\mathrm{OH}) \mathrm{D}<20 \mathrm{ng} / \mathrm{mL}$, insufficiency as $20-29 \mathrm{ng} / \mathrm{mL}$ and sufficiency as $\geq 30 \mathrm{ng} / \mathrm{mL}$. The data compiled here are also stratified by geographic locale of the study subjects, to press home the fact that vitamin D deficiency is widespread throughout the nation, irrespective of diverse dietary and social practices. For instance, despite fish being a staple diet in Bengal (eastern India) vitamin D nutrition is no better than in other regions. Geographical stratification of data also indicates regions of the country from where more data is needed. The effectiveness or failure of vitamin D supplementation and food fortification in restoring vitamin D levels and bone health have been reviewed, while making the case that vitamin D deficiency needs to be recognized as a public health problem. This review also discusses the need and feasibility of fortification of staple foods with vitamin D in India. Steps to be taken by the policymakers in India are also mentioned. Data, when available, from other countries of the Indian subcontinent are also compiled and presented for comparison.

\section{Vitamin D Metabolism}

Vitamin D can be synthesized in sufficient amounts by most vertebrates on adequate exposure of the skin to sunlight (UVB rays). It is critical that most vertebrates obtain a sufficient amount of vitamin D either from their diet or from adequate exposure of the skin to sunlight. The term "vitamin D" refers to compounds vitamin $\mathrm{D}_{3}$ (cholecalciferol) or vitamin $\mathrm{D}_{2}$ (ergocalciferol). Vitamin $\mathrm{D}_{3}$ is produced in the skin on exposure to sunlight. Vitamin $\mathrm{D}_{3}$ is derived from 7-dehydrocholesterol by ultraviolet irradiation of the skin. Vitamin $\mathrm{D}_{3}$ is also found in animal food sources e.g., fatty fish (e.g., salmon, mackerel and tuna) cod liver oil, milk, etc. Vitamin $\mathrm{D}_{2}$ is found in vegetal sources like sun-exposed yeast and mushrooms. Notably, most dietary sources are not sufficiently rich in their vitamin D content.

Vitamin $\mathrm{D}$ (both forms $\mathrm{D}_{3}$ or $\mathrm{D}_{2}$ ) is a prohormone which requires two hydroxylations to finally attain its biologically active form $-1,25(\mathrm{OH})_{2} \mathrm{D}$. The first hydroxylation occurs in the liver, at position C25 to form 25-hydroxyvitamin D, also known as $25(\mathrm{OH}) \mathrm{D}$ or calcidiol. $25(\mathrm{OH}) \mathrm{D}$ is the major circulating form of vitamin $\mathrm{D}$. The second hydroxylation occurs at position $\mathrm{C} 1 \alpha$ to form $1,25(\mathrm{OH})_{2} \mathrm{D}$, also known as calcitriol. $1,25(\mathrm{OH})_{2} \mathrm{D}$ is produced primarily but not exclusively in the kidneys. $1,25(\mathrm{OH})_{2} \mathrm{D}$ is released in blood, where it binds to vitamin $\mathrm{D}$ binding protein (DBP) and reaches its target tissues to exert its endocrine functions through the vitamin $\mathrm{D}$ receptor (VDR). $1,25(\mathrm{OH})_{2} \mathrm{D}$ is also produced in several extrarenal tissues for its paracrine and autocrine functions. Most cells in the body have VDR. Many cell types can also produce $1,25(\mathrm{OH})_{2} \mathrm{D}$. $1,25(\mathrm{OH})_{2} \mathrm{D}$ is capable of regulating a wide variety of genes that have important functions in regulating cell growth and differentiation.

\section{Vitamin D and Skeletal Health}

Rickets, osteomalacia and osteoporosis are widely prevalent all over the world. The most well recognized function of $1,25(\mathrm{OH})_{2} \mathrm{D}$ involves regulation of calcium and phosphorus balance for bone mineralization and remodeling. Without adequate levels of $1,25(\mathrm{OH})_{2} \mathrm{D}$ in the bloodstream, dietary calcium cannot be absorbed. Low calcium levels lead to an increase in serum PTH concentration, which leads to increased tubular reclamation of calcium in kidneys and resorption from the skeleton at the cost of lowering bone density. In the long term this leads to weakened and brittle bones that break easily. Approximately $40 \%-60 \%$ of total skeletal mass at maturity is accumulated during childhood 
and adolescence. Rickets results from inadequate mineralization of growing bone. Thus it is a childhood disease and it is manifested as bone deformities, bone pain and weakness. Biochemical abnormalities consistently include hypophosphatemia, elevated alkaline phophatase levels and serum $25(\mathrm{OH}) \mathrm{D}$ levels are usually below $5 \mathrm{ng} / \mathrm{mL}$. Chronic vitamin D deficiency in adults results in osteomalacia, osteoporosis, muscle weakness and increased risk of falls [4-11]. Epidemiological support for skeketal benefits of vitamin $\mathrm{D}$ is well known [5,6,12-14].

\section{Vitamin D: Extraskeletal Effects}

Biochemical studies have implicated vitamin D deficiency in many chronic diseases including, but not limited to, infectious diseases, autoimmune diseases, cardiovascular diseases, diabetes and cancer. Numerous epidemiological publications support the extraskeletal benefits of vitamin D and they cannot be ignored even though majority of these are association studies or small randomized controlled trials. Nevertheless, stronger evidence is required with the aid of more robust and reliable statistical methods such as randomized controlled trials (RCTs). These RCTs should be well-designed, well-executed and conducted worldwide to generate dependable and incontrovertible data, in order to assess the benefits of vitamin D supplementation not only as a preventive measure but also as adjuvant therapies $[12,15,16]$.

\subsection{Immunity}

As early as in the 19th century, cod liver oil (a rich source of vitamin D) was used for treating tuberculosis (TB). Skin exposure to sunlight was an effective therapy for treating Mycobacterium infections of the skin. In 1903, Finsen received the Nobel Prize for demonstrating that Lupus vulgaris, the epidermal form of TB, could be cured using light from an electric arc lamp. In early 1900s, growing awareness of benefits of sun exposure pertaining treatment of infectious diseases led to the development of sanatoriums in "sun-rich areas". These sanatoriums enabled regimented sun exposure, diet and exercise. These sanatoriums primarily hosted TB patients [17]. Recent studies have linked vitamin D deficiency with increased risk of developing TB [18,19], otitis media [20], upper respiratory tract infections [21] and influenza [22].

\subsection{Cardiovascular Health}

Cardiovascular diseases (CVDs), including heart failure and coronary artery disease are a major cause of morbidity and mortality worldwide. There is accumulating epidemiological evidence from observational studies suggesting that CVDs are associated with vitamin D deficiency [23,24]. Increased risk of hypertension was associated with living at higher latitudes [25]. 25(OH)D level $<21 \mathrm{ng} / \mathrm{mL}$ was associated with increased risk of hypertension, diabetes, obesity and high triglyceride levels - all associated with increased cardiovascular mortality [26]. Various studies have reported reduced $25(\mathrm{OH}) \mathrm{D}$ concentrations in patients with previous and prevalent cardiovascular or cerebrovascular diseases [15,27]. 


\subsection{Type 1 Diabetes}

Type 1 diabetes (T1D) is caused by autoimmune destruction of pancreatic $\beta$ cells, which eventually leads to insulin-dependent diabetes. Higher rates of incidence of T1D were observed at higher latitudes worldwide [28,29]. Epidemiological association of vitamin D intake and reduced risk of T1D was also seen [30]. A meta-analysis of observational studies showed a $30 \%$ reduction in risk of T1D in children receiving vitamin $\mathrm{D}$ supplements [31].

\subsection{Type 2 Diabetes}

Type 2 diabetes (T2D) is marked by insulin resistance (IR). In IR insulin is adequately or overproduced by pancreatic $\beta$ cells, but is ineffectively utilized by the target cells of adipose, hepatic and skeletal muscles tissues. As a response to hyperglycemia, $\beta$ cells further increase insulin production leading to hyperinsulinemia, which is often indicative of a pre-(T2D) stage. Hyperinsulinemia is associated with hypertension, obesity, dyslipidemia, and glucose intolerance [32]. These conditions are collectively known as "metabolic syndrome" [33]. A meta-analysis of observational studies showed inverse relation of $25(\mathrm{OH}) \mathrm{D}$ levels and calcium status with insulin resistance and hyperglycemia. In this meta-analysis, supplementation with both the nutrients combined showed benefit in optimizing glucose levels [34].

\subsection{Cancer}

Adults living at higher latitudes are more likely to develop and die of colorectal cancer [35,36], prostate cancer [37], ovarian cancer [38], breast cancer [39], lung cancer [40] and esophageal cancer [41]. Retrospective and prospective epidemiologic studies showed that when $25(\mathrm{OH}) \mathrm{D}$ levels were $<20 \mathrm{ng} / \mathrm{mL}$ there was a $30 \%-50 \%$ increased risk of developing and dying of colorectal, prostate, breast, pancreatic, and esophageal cancer $[36,39,42-45]$.

\section{Serum 25(OH)D Levels as Indicative of Vitamin D Deficiency, Insufficiency or Sufficiency}

Maintenance of adequate levels of serum $25(\mathrm{OH}) \mathrm{D}$ is essential to sustain the claimed pleiotropic effects, whether skeletal (classical) or extra-skeletal (non-classical). The threshold levels of serum $25(\mathrm{OH}) \mathrm{D}$ required to optimize its effects may not be the same in the various target organs. Based on classical skeletal effects, vitamin D deficiency is defined as serum levels of $25(\mathrm{OH}) \mathrm{D}<20 \mathrm{ng} / \mathrm{mL}$ $(50 \mathrm{nmol} / \mathrm{L})$ with consequent and consistent elevation of PTH and reduction in intestinal calcium absorption. Vitamin D insufficiency is defined as serum 25(OH)D levels in the range of 20-29 ng/mL. At serum 25(OH)D levels of $30 \mathrm{ng} / \mathrm{mL}$ intestinal calcium absorption reaches its peak, and PTH levels continue to fall until this level of $25(\mathrm{OH}) \mathrm{D}$ is attained. Thus, vitamin $\mathrm{D}$ sufficiency is defined as serum levels of $25(\mathrm{OH}) \mathrm{D} 30-32 \mathrm{ng} / \mathrm{mL}$. A desirable and safe range of serum $25(\mathrm{OH}) \mathrm{D}$ levels would be 30-100 ng/mL. This range would be sufficient for most known effects of vitamin D and also significantly lower to obviate concerns pertaining vitamin $\mathrm{D}$ toxicity. 


\section{Vitamin D Supplements and Efficacy Concerns}

Commercially, vitamin $\mathrm{D}_{2}$ is manufactured by ultraviolet irradiation of ergosterol from yeast. Vitamin $\mathrm{D}_{3}$ is produced by the ultraviolet irradiation of 7-dehydrocholesterol from lanolin. Both forms of vitamin D are available as vitamin D supplements. Several other forms of vitamin D supplements are also available. $1,25(\mathrm{OH})_{2} \mathrm{D}$ is indicated specifically for patients with renal diseases and $25(\mathrm{OH}) \mathrm{D}$ is useful when hepatic hydroxylation of vitamin $\mathrm{D}$ is impaired.

Whether $\mathrm{D}_{2}$ or $\mathrm{D}_{3}$, is more efficacious in raising and sustaining serum $25(\mathrm{OH}) \mathrm{D}$ levels, remains controversial. Several studies have proved equivalence between the two forms [46-49]. However, other studies reported that $\mathrm{D}_{3}$ is more effective than $\mathrm{D}_{2}$ in achieving and maintaining higher serum 25(OH)D levels [50-53]. Nevertheless, on a long term basis either form may be used, bearing in mind the long half-life $(2-3$ weeks $)$ of $25(\mathrm{OH}) \mathrm{D}$ in circulation.

\section{Testing Vitamin D Status}

Plasma 25(OH)D or calcidiol (a summation of $\mathrm{D}_{3}$ and $\mathrm{D}_{2}$ forms) is the most reliable marker of vitamin D status. Immunoassays such as radioimmunoassay (RIA), enzyme linked immunosorbant assay (ELISA), chemiluminescence immunoassay and protein binding assays are used in routine testing of $25(\mathrm{OH}) \mathrm{D}$ in clinical laboratories. LCTMS (liquid chromatography tandem mass spectrometry) is the widely accepted reference method for $25(\mathrm{OH}) \mathrm{D}$ measurement. However, LCTMS is tedious, expensive and time consuming and therefore seldom used commercially.

Since vitamin D undernutrition is largely silent and subclincal, the indication for testing remains controversial. At present 25(OH)D test is the "most ordered test" in the USA. A similar trend has just begun in the upper socioeconomic stratum in India too. This clearly shows increasing awareness pertaining widespread prevalence of vitamin D deficiency among Indian clinicians. A $25(\mathrm{OH}) \mathrm{D}$ test using antibody based technologies in India costs an individual approximately INR 1500, which is unaffordable for most Indians. Surely, vitamin D status needs to be improved in most individuals in India and not just the privileged or a select few. However, testing every individual's vitamin D levels, in a population with such a high prevalence of vitamin D deficiency is not economically and practically feasible. Furthermore, whether subclinical vitamin D deficiency in otherwise healthy individuals should be treated or not, and to what target level of serum $25(\mathrm{OH}) \mathrm{D}$ remains controversial. It will be more cost-effective to implement aggressive nationwide vitamin D supplementation and food fortification programs for the benefit of all ostensibly healthy individuals.

\section{Vitamin D Status of Ostensibly Healthy Indians}

Countrywide studies (Table 1) have reported vitamin D deficiency in as high as $70 \%-100 \%$ of ostensibly healthy individuals. High prevalence of vitamin D deficiency was reported from northern to southern and western to eastern India, in ostensibly healthy children, adolescents, young adults and those $\geq 50$ years old. All over India, vitamin D deficiency was highly prevalent in pregnant women and lactating mothers. Vitamin D status of these mothers correlated well with their neonates and their exclusively breastfed infants. Subjects from rural and urban areas presented a similar picture. Relatively, fish are a rich source of vitamin D. The residents of Bengal (eastern India) eat more fish 
compared to the rest of the Indians. Surprisingly, their vitamin D status appears to be just as poor as in the rest of the country [54]. Similarly, even healthy young soldiers with sufficient intake of calcium, adequate sun exposure and regular exercise regimen were found to be vitamin D deficient $[55,56]$, as were young sportswomen [57]. Among resident doctors from Mumbai (western India) [58] and also doctors from eastern India [54], most were vitamin D deficient. Vitamin D deficiency was also observed in most of 2119 healthcare professionals studied from all over India [59]. Evidently, countrywide prevalence of vitamin D deficiency is undeniable.

\section{Correlation of Vitamin D Status with Bone Health of Ostensibly Healthy Adolescents and Adults in India}

Among otherwise healthy adolescents and adults studied, along with low serum $25(\mathrm{OH}) \mathrm{D}$ levels, a significant number of subjects also revealed other biochemical and clinical manifestations of vitamin $\mathrm{D}$ deficiency. Biochemical evidences of suboptimal bone health are: elevated alkaline phosphatase, a surrogate marker for increased bone turnover, and elevated PTH levels (secondary hyperparathyroidism or SHPT). ALP and PTH were often reported in research papers, especially with respect to their correlation with vitamin $\mathrm{D}$ status. However, the most accurate and convincing evidence of bone density is DEXA. Only research articles reporting BMD, as measured by DEXA, in the context of vitamin D status of ostensibly healthy individuals are included in this section (Table 2). Vitamin D intervention studies that measured resultant BMD outcomes are discussed later in section 15 of this review.

Most studies did not show any correlation of BMD with vitamin D status. Notably, among 90 adults, who were 20-30 year-old soldiers from Indian paramilitary forces, with adequate nutrition, sun exposure and physical exercise, BMD was lower when compared to Caucasians. Among men, osteopenia was noted in $50 \%$ at the lumbar spine, $35 \%$ at the hip, and $50 \%$ at the forearm. Additionally, $10 \%$ of men had osteoporosis of the lumbar spine. Among women, osteopenia was noted in $32 \%$ at the lumbar spine, $14 \%$ at the hip and $21 \%$ at the forearm. The authors speculated that the effect of childhood malnutrition may have contributed to lower peak bone mass accumulation in these subjects [56]. BMD studies emphatically underline the need for adequate nutrition, sun exposure and physical exercise from the very beginning of one's life, to attain peak bone mass, and later to maintain it. Indubitably, vitamin D status in India is grim and needs to be reckoned with.

\section{Vitamin D Sufficiency via Sun Exposure Is Not a Tenable Solution for Most Indians}

Vitamin D deficiency is a major health concern in India, notwithstanding the brightly shining sun. The "adequacy of exposure to sunlight of an individual's bare skin" required to photosynthesize vitamin D is grossly ill understood. Darker skin has high melanin content which acts as a natural sunscreen. Therefore, darker skin produces a significantly lesser amount of vitamin D when compared with the individuals with fairer skin, such as Caucasians [60-62]. Thus, for Indian skin tone, minimum "direct sun exposure" required daily is more than $45 \mathrm{~min}$ to bare face, arms and legs to sun's UV rays (wavelength 290-310 nm). With the exception of those who perforce need to work outdoors in the sun, most Indians do not get adequate sun exposure to produce sufficient amounts of vitamin D endogenously. Indian social and or religious norms related to public modesty dictate that most parts of 
an individual's body, irrespective of gender, be covered. The not so D-lightful price of urbanization -in big cities a majority of people live in very high population density areas. They perforce live in overcrowded tenements, which are closely packed and 3-4 stories high. Consequently, direct sunlight does not reach inside most parts of the dwellings, thereby disallowing any sun exposure to an individual in the privacy of one's home. Additionally, lack of space offers limited options for outdoor activities. Atmospheric pollution of metropolitan India also factors in with respect to vitamin D status [63]. Use of sunscreen creams and umbrellas do not help either. The extreme discomfort of the scorching heat associated with most sunny days of Indian summer and (not to mention) the undying desire of most Indians to attain a fairer skin complexion instantly extinguish any desire for sun exposure, and a person's primary focus is on finding ways to avoid the sun, at all costs. In the blazing heat of India these two concerns score very high and the quest for vitamin D sufficiency takes a backseat, always. Therefore, in the Indian scenario, vitamin D sufficiency cannot be attained by depending on adequate sun exposure.

\section{Nutritional Factors Attributing to High Prevalence of Vitamin D Deficiency in India}

Vitamin D sufficiency by dietary intake is the only tenable solution for Indians. However, this solution itself has a barrage of problems.

- Most dietary sources of vitamin D have very low vitamin D content. Most of the food items rich in vitamin D are of animal origin. Most Indians are vegetarians. Commonly, a dietary source of vitamin D for vegetarians is milk, provided milk has been fortified with vitamin D. Milk is rarely fortified with vitamin $\mathrm{D}$ in India. The vitamin $\mathrm{D}$ content of unfortified milk is very low (2 IU/100 mL). Additionally, milk and milk products are unaffordable to the socioeconomically underprivileged. Another concern in India is the rampant dilution and/or adulteration of milk and milk products.

- Low calcium in Indian diet: Low dietary intake of calcium in conjunction with vitamin D insufficiency is associated with secondary hyperparathyroidism (SHPT). SHPT is further exacerbated by induced destruction of $25(\mathrm{OH}) \mathrm{D}$ and $1,25(\mathrm{OH})_{2} \mathrm{D}$ by 24 hydroxylase [64]. 24 hydroxylase is the key enzyme of vitamin $\mathrm{D}$ catabolism and is regulated by $1,25(\mathrm{OH})_{2} \mathrm{D}, \mathrm{PTH}$ and FGF23 (Fibroblast Growth Factor 23) levels. FGF23 is a phosphate regulator. High serum phosphate levels increase production of FGF23 in bone osteocytes via the action of $1,25(\mathrm{OH})_{2} \mathrm{D}$. Subsequently, FGF23 reduces renal phosphate resorption, indirectly suppresses intestinal phosphate absorption and also suppresses PTH and $1,25(\mathrm{OH})_{2} \mathrm{D}$ synthesis. Overproduction of FGF23 can result in increased morbidity associated with vitamin D deficiency [65]. This regulatory mechanism may explain the low $25(\mathrm{OH}) \mathrm{D}$ levels in rural subjects on a high phytate and/or low calcium diet, despite plentiful sun exposure. Most studies reported calcium intake much lower than the RDA (Recommended Daily Allowance) defined by the Indian Council of Medical Research (ICMR). Only two studies reported adequate calcium intake. In both these publications the study subjects were paramilitary soldiers $[55,56]$. ICMR's RDA for calcium intake in India is lower than that of the western world.

- Calcium balance is a function of intake and excretion [66,67]. Even though the Indian diet is low in calcium content, it also has a lower protein content and therefore low endogenous 
acid production, which may reduce urinary calcium loss. Therefore, the amount of dietary calcium required to maintain calcium balance may be lower than for those in the Occident. The protein-induced alterations in calcium homeostasis (and possibly in bone mass) have been attributed to increments in endogenous acid production and net acid excretion due to the oxidation of the constituent sulfur containing amino acids. On the other hand, the high salt content of Indian diet is likely to increase urinary calcium excretion. A direct relation between high sodium intake and lower bone mass has been reported [68].

- Intake of caffeine from tea and coffee is very high in India. Most Indians consume milk as part of their tea or coffee. The proportion of milk is very low in these drinks. Thus calcium intake through these beverages is low. Vitamin D is stable during cooking. It is stable up to $200{ }^{\circ} \mathrm{C}$. However, thermal stability of vitamin $\mathrm{D}$ is an inverse function of both temperature and time. In India, milk is boiled for several minutes before consumption. Before the same lot of milk is consumed in entirety, it is subjected to two-three rounds of boiling. In India most of the times, beverages like tea and coffee are boiled for several minutes to get the right flavor. This boiling may reduce the content of any vitamin D that there may have been left after boiling of the milk itself. Therefore, these beverages may not contribute significantly to either calcium or vitamin D intake in Indians. Vitamin D is a fairly robust vitamin. The preceding statements about its thermal degradation have been made as precautionary stance to not overstate the thermal robustness of this micronutrient. Additionally, studies have reported association of high caffeine intake with increased risk of low bone mineral density, osteoporosis, and osteoporotic fractures in middle-aged women. This situation is exacerbated in women with low calcium intake, especially in lean subjects [69].

- High prevalence of lactose intolerance in India is a major deterrent pertaining milk consumption, further lowering intake of calcium and vitamin D in these individuals. Ethnic and geographic variations of lactose intolerance were observed, with a higher prevalence in southern (Dravidian descent) and eastern India compared to northern India (Aryan descent) [70-73].

- Indian diet has high phytate content. Phytate is the principal storage form of phosphorus in many plant tissues, especially the bran portion of grains and other seeds. Phytate is indigestible to humans. Phytates chelate micronutrients such as calcium and iron, and thus reduce intestinal absorption of these nutrients. Benefits of sun exposure in rural subjects owing to an agrarian life were seen by significantly higher $25(\mathrm{OH}) \mathrm{D}$ levels [74]. However, possibly owing to high phytate content in diet, these levels were still insufficient in most individuals. Possibly, high phytate content in the diet of soldiers in northern India may have contributed to their vitamin D insufficiency, despite adequate sun exposure, nutrition and physical exercise [56].

- Notably, nearly all studies pertaining vitamin D status in healthy subjects reported a high phytate/calcium intake ratio. What Indians may require is a higher intake of calcium in their diet to lower the phytate/calcium intake ratio. Dietary habits in India have changed significantly. Many people remove a substantial proportion of bran from whole wheat flour before kneading to improve texture and fluffiness of chapatis (unleavened flat bread). Consumption of white bread is also very high. Most people prefer processed, split and polished pulses to whole seeds due to the ease of shorter time required for cooking and the consequent lowered expense of cooking 
fuel. Consumption of instant (or not) noodles and burgers also is on the rise across all socio-economic strata, with the exception of the impecunious.

- High phytate in Indian diet especially among the socio-economically lower classes stems from the elementary and immediate need of sufficiency of the calorific need. Cereals and legumes are more affordable and easily available than vegetables, milk and other dairy products. Besides, they are sources of protein for the vegetarians. Many cereals are also sources of calcium, however due to chelation by phytates its bioavailability is limited.

- In the scenario of inadequate calcium intake, vitamin D insufficiency and high phytate content in diet, environmental pollutants such as fluoride add insult to injury. Toxins like fluoride affect bone metabolism severely in the conjunction with inadequate calcium intake, especially in children $[75,76]$.

- Cooking practices in India: Indians in general adhere to traditional cooking styles and practices, irrespective of their migration to any part of the world. In tropical climate perishable food items putrefy quickly. Notably, in India there is no perceptible government regulation on the hygiene and microbial quality control of fresh produce that reaches from the producer to the end-consumer. Consumption of uncooked fresh produce, especially vegetables, milk, etc., is generally considered ill-advised. As in the rest of the world, in India too, slow cooking is widely practiced. This culinary practice, however, is ill-advised bearing in mind the thermal instability of many vitamins. As mentioned earlier vitamin D is degraded at temperatures above $200{ }^{\circ} \mathrm{C}$. Its thermal stability is inversely related to temperature and time. Cooking gas flame reaches temperature above $1900{ }^{\circ} \mathrm{C}$ and coal stove heat reaches $300-700{ }^{\circ} \mathrm{C}$. Water boils at $100{ }^{\circ} \mathrm{C}$. Baking is done mostly above $175^{\circ} \mathrm{C}$ but the temperature in the food does not reach such high temperatures, therefore stability of vitamin D during baking is well within acceptable range [77]. Pertaining shallow and deep-frying of food, most cooking fats and oils have smoke points above $180^{\circ} \mathrm{C}$. Shallow and deep frying of foods is very popular in India. When foods are fried, vitamin D in the food comes out into the cooking medium and is thermally degraded [78]. Pressure cooking temperatures vary depending on the pressure withstood by the cooker used and may range from $100{ }^{\circ} \mathrm{C}$ to $120{ }^{\circ} \mathrm{C}$. Short-time (as short as possible) pressure cooking is definitely advisable to retain at least some of the thermally more stable essential nutrients in cooked food, including vitamin D.

- Protein malnutrition and poor overall nutrition resulting from poverty: Perforce, in the sordid context of poverty, focus on a balanced diet is always on the back burner. It is very convenient to attribute dietary patterns or cooking traditions, than face a reality as grim as poverty. Factually, balanced diet is only an occasional treat to the impecunious. An old adage, "When a poor man eats chicken, one of them is sick", says it all.

- Publications indicating wide prevalence of vitamin D deficiency in healthy Indians have studied subjects mostly from lower and upper middle classes. Individuals below poverty line were not represented well in these studies. Hence, poor nutrition observed in these studies may also stem from lack of awareness of the features, benefits and necessity of balanced nutrition. 
Table 1. Vitamin D status of ostensibly healthy Indians. All 25(OH)D values have been shown in $\mathrm{ng} / \mathrm{mL}$. To convert from $\mathrm{nM}$ to $\mathrm{ng} / \mathrm{mL}$, $\mathrm{nM}$ values were divided by (2.5). Vitamin D deficiency is defined as $25(\mathrm{OH}) \mathrm{D}<20 \mathrm{ng} / \mathrm{mL}$, insufficiency as $20-29 \mathrm{ng} / \mathrm{mL}$ and sufficiency as $\geq 30 \mathrm{ng} / \mathrm{mL} ;{ }^{\ddagger}$ Information available from the abstract of the article. Age of the subjects is in mean age (SD) years, unless otherwise indicated.

\begin{tabular}{|c|c|c|c|c|c|c|c|}
\hline \multirow[b]{2}{*}{ Locale } & \multirow{2}{*}{\multicolumn{2}{|c|}{ Study Subjects }} & \multirow{2}{*}{$\begin{array}{c}25(\mathrm{OH}) \mathrm{D} \\
(\mathrm{ng} / \mathrm{mL}) \\
\text { Mean (SD) } \\
\end{array}$} & \multicolumn{3}{|c|}{ Vitamin D Status } & \multirow[b]{2}{*}{ Reference } \\
\hline & & & & $\%$ deficient & $\%$ insufficient & $\%$ sufficient & \\
\hline \multicolumn{8}{|c|}{ Northern India } \\
\hline \multirow{6}{*}{$\begin{array}{l}\text { Kashmir } \\
\left(34.3^{\circ} \mathrm{N}\right)\end{array}$} & Total $N=92$ & Adults, age 28.15 (4.9) years. & - & 83 & - & - & \multirow{6}{*}{$\begin{array}{l}\text { Zargar } \\
2007[79]\end{array}$} \\
\hline & $N=64$ & $\mathrm{M}$ & $15.06(12.0)$ & 76.6 & - & - & \\
\hline & $N=28$ & $\mathrm{~F}$ & $5.51(4.42)$ & 94.4 & - & - & \\
\hline & $N=50$ & Urban subjects & $11.26(9.65)$ & 85.7 & - & - & \\
\hline & $N=42$ & Rural subjects & $12.84(12.39)$ & 80 & - & - & \\
\hline & $\begin{array}{l}N=17 \\
N=23 \\
N=15 \\
N=23 \\
N=14\end{array}$ & $\begin{array}{l}\text { Occupation: } \\
\text { Rural/farmer, } 17 \mathrm{M} / 0 \mathrm{~F} \\
\text { Government employee, } 20 \mathrm{M} / 3 \mathrm{~F} \\
\text { Household, } 0 \mathrm{M} / 15 \mathrm{~F} \\
\text { Medical professional, } 16 \mathrm{M} / 7 \mathrm{~F} \\
\text { Student } 11 \mathrm{M} / 3 \mathrm{~F}\end{array}$ & $\begin{array}{l}- \\
- \\
- \\
- \\
-\end{array}$ & $\begin{array}{l}70.6 \\
69.6 \\
100 \\
91.3 \\
85.3 \\
\end{array}$ & $\begin{array}{l}- \\
- \\
- \\
-\end{array}$ & $\begin{array}{l}- \\
- \\
- \\
- \\
-\end{array}$ & \\
\hline \multirow{3}{*}{$\begin{array}{l}\text { Punjab } \\
\left(31.1^{\circ} \mathrm{N}\right) \& \\
\text { Haryana } \\
\left(29^{\circ} \mathrm{N}\right)\end{array}$} & Total $N=90$ & $\begin{array}{l}\text { Adults, paramilitary soldiers. Adequate diet, sun exposure } \\
\text { and physical exercise. }\end{array}$ & - & - & - & - & \multirow[t]{3}{*}{$\begin{array}{l}\text { Tandon } \\
2003[56]\end{array}$} \\
\hline & $N=40$ & $\mathrm{M}$, in winter, age $22.7(2.8)$ years. & $18.4(5.3)$ & - & - & - & \\
\hline & $N=50$ & $\mathrm{~F}$, in summer, age 23.4 (3.1) years. & $25.3(7.4)$ & - & - & - & \\
\hline \multirow[t]{2}{*}{$\begin{array}{l}\text { Chandigarh } \\
\left(30.7^{\circ} \mathrm{N}\right.\end{array}$} & Total $N=329$ & $\begin{array}{l}\text { Young urban adults, age } 18-25 \text { years, at the end of } \\
\text { summer }\end{array}$ & $52.9(33.7)$ & - & - & $72.5 \%$ & \multirow[t]{2}{*}{$\begin{array}{l}\text { Ramakrishnan } \\
2011[80]\end{array}$} \\
\hline & $N=237$ & Subjects from the same cohort at the end of winter & $31.8(21.1)$ & - & - & $50.7 \%$ & \\
\hline
\end{tabular}


Table 1. Cont.

\begin{tabular}{|c|c|c|c|c|c|c|c|}
\hline \multirow[b]{2}{*}{ Locale } & \multirow{2}{*}{\multicolumn{2}{|c|}{ Study Subjects }} & \multirow{3}{*}{ 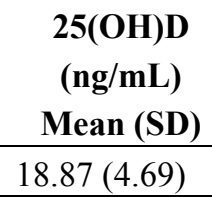 } & \multicolumn{3}{|c|}{ Vitamin D Status } & \multirow[b]{2}{*}{ Reference } \\
\hline & & & & $\%$ deficient & $\%$ insufficient & $\%$ sufficient & \\
\hline \multirow{6}{*}{$\begin{array}{l}\text { Delhi } \\
\left(28.3^{\circ} \mathrm{N}\right)\end{array}$} & $N=31$ & Urban adults, M, age 25 (5) years, soldiers, winter & & - & - & - & \multirow{6}{*}{$\begin{array}{l}\text { Goswami } \\
2000[55]\end{array}$} \\
\hline & $N=15$ & $\begin{array}{l}\text { Urban adults, } 10 \mathrm{M}+5 \mathrm{~F} \text {, age } 43(16) \text { years, depigmented } \\
\text { persons, winter }\end{array}$ & $7.28(4.49)$ & - & - & - & \\
\hline & $N=19$ & $\begin{array}{l}\text { Urban adults, } 11 \mathrm{M}+8 \mathrm{~F} \text {, age } 23(5) \text { years, physicians and } \\
\text { nurses, winter }\end{array}$ & $3.19(1.39)$ & - & - & - & \\
\hline & $N=19$ & $\begin{array}{l}\text { Urban adults, } 11 \mathrm{M}+8 \mathrm{~F} \text {, age } 24 \text { (4) years, physicians and } \\
\text { nurses, summer }\end{array}$ & $7.17(3.19)$ & - & - & - & \\
\hline & $N=29$ & $\begin{array}{l}\text { Urban adult F/mothers, age } 23 \text { (5) years, low income, } \\
\text { summer }\end{array}$ & $8.76(4.29)$ & - & - & - & \\
\hline & $N=29$ & Newborns of the mothers studied, $16 \mathrm{M}+13 \mathrm{~F}$, summer & $6.68(1.99)$ & - & - & - & \\
\hline \multirow{3}{*}{$\begin{array}{l}\text { Agota } \\
\text { village } \\
\left(29^{\circ} \mathrm{N}\right) \\
80 \mathrm{~km} \text { from } \\
\text { Delhi }\end{array}$} & Total $N=57$ & Rural Adults & $14.56(9)$ & 68.5 & - & - & \multirow{3}{*}{$\begin{array}{l}\text { Goswami } \\
2008[81]\end{array}$} \\
\hline & $N=32$ & $\mathrm{M}$, rural, age $42.8(16.6)$ years & $17.68(9.76)$ & - & - & - & \\
\hline & $N=25$ & F, rural, age 43.4 (12.6) years & $10.76(6.86)$ & - & - & - & \\
\hline \multirow{3}{*}{$\begin{array}{l}\text { Delhi } \\
\left(28.3^{\circ} \mathrm{N}\right)\end{array}$} & Total $N=186$ & Young adults $F$, age $18.6(1.3)$ years & $12.96(9.84)$ & - & - & - & \multirow{3}{*}{$\begin{array}{l}\text { Marwaha } \\
2011[57]\end{array}$} \\
\hline & $N=90$ & Sports-girls from colleges & $21.2(7.57)$ & - & - & - & \\
\hline & $N=96$ & College girls & $5.16(3.08)$ & 100 & 0 & 0 & \\
\hline \multirow{3}{*}{$\begin{array}{l}\text { Delhi } \\
\left(28.3^{\circ} \mathrm{N}\right)\end{array}$} & Total $N=642$ & Urban adults, middle income group & $7(4.08)$ & - & - & - & \multirow{3}{*}{$\begin{array}{l}\text { Goswami } \\
2009[82]\end{array}$} \\
\hline & $N=244$ & Adult M, age 31.4 (13.4) years & $7.2(3.64)$ & - & - & - & \\
\hline & $N=398$ & Adult F, age $35.1(13.4)$ years & $6.88(4.36)$ & - & - & - & \\
\hline \multirow{3}{*}{$\begin{array}{l}\text { Delhi } \\
\left(28.3^{\circ} \mathrm{N}\right)\end{array}$} & Total $\mathrm{N}=105$ & Urban adults, middle income group, age 43.3 (9.7) years & $9.8(6.0)$ & 94.3 & - & - & \multirow{3}{*}{$\begin{array}{l}\text { Vupputuri } \\
2006[83]\end{array}$} \\
\hline & $N=51$ & $\mathrm{M}$, indoor workers & $10.8(6.8)$ & - & - & - & \\
\hline & $N=54$ & F, housewives & $8.8(4.9)$ & - & - & - & \\
\hline \multirow{3}{*}{$\begin{array}{l}\text { Delhi } \\
\left(28.3^{\circ} \mathrm{N}\right)\end{array}$} & Total $N=404$ & Adolescents, F, urban, age 12.3 (3.4) years & $12.74(6.17)$ & 90.8 & - & - & \multirow{3}{*}{$\begin{array}{l}\text { Puri } \\
2008[84]\end{array}$} \\
\hline & $N=193$ & Low income level & $13.84(6.97)$ & 89.6 & - & - & \\
\hline & $N=211$ & Higher income level & $11.75(5.07)$ & 91.9 & - & - & \\
\hline
\end{tabular}


Table 1. Cont.

\begin{tabular}{|c|c|c|c|c|c|c|c|}
\hline \multirow[b]{2}{*}{ Locale } & \multirow{2}{*}{\multicolumn{2}{|c|}{ Study Subjects }} & \multirow{3}{*}{$\begin{array}{c}\begin{array}{c}25(\mathrm{OH}) D \\
(\mathbf{n g} / \mathbf{m L}) \\
\text { Mean }(\mathrm{SD})\end{array} \\
11.8(7.2) \\
\end{array}$} & \multicolumn{3}{|c|}{ Vitamin D Status } & \multirow[b]{2}{*}{ Reference } \\
\hline & & & & $\%$ deficient & $\%$ insufficient & $\%$ sufficient & \\
\hline \multirow{3}{*}{$\begin{array}{l}\text { Delhi } \\
\left(28.3^{\circ} \mathrm{N}\right)\end{array}$} & Total $N=5137$ & Adolescents, urban, school children, age $10-18$ years & & - & - & - & \multirow{3}{*}{$\begin{array}{l}\text { Marwaha } \\
2005[85]\end{array}$} \\
\hline & $N=3089$ & Lower income level, $1079 \mathrm{M}, 2010 \mathrm{~F}$ & $10.4(0.4)$ & 92.6 & - & - & \\
\hline & $N=2048$ & Higher income level, $968 \mathrm{M}, 1080 \mathrm{~F}$ & $13.7(0.4)$ & 84.9 & - & - & \\
\hline \multirow{3}{*}{$\begin{array}{l}\text { Delhi } \\
\left(28.3^{\circ} \mathrm{N}\right)\end{array}$} & Total $N=664$ & Urban adolescent $\mathrm{F}$, school girls, age $12.8(2.7)$ years & $11.4(5.8)$ & - & - & - & \multirow{3}{*}{$\begin{array}{l}\text { Marwaha } \\
2007[86]\end{array}$} \\
\hline & $N=369$ & Lower income level, age $12.8(2.7)$ years & $11.1(5.2)$ & - & - & - & \\
\hline & $N=295$ & Higher income level, age 12.7 (2.6) years & $11.8(6.4)$ & - & - & - & \\
\hline \multirow[t]{3}{*}{$\begin{array}{l}\text { Delhi } \\
\left(28.3^{\circ} \mathrm{N}\right)\end{array}$} & Total $N=1346$ & $\begin{array}{l}\text { Urban adults } \geq 50 \text { years, } 643 \mathrm{M}, 703 \mathrm{~F} \text {, age } 58(9.5) \text { years } \\
\text { (range } 50-84 \text { years) }\end{array}$ & $9.79(7.61)$ & 91.2 & 6.8 & 2 & \multirow[t]{3}{*}{$\begin{array}{l}\text { Marwaha } \\
2011[87]\end{array}$} \\
\hline & $N=995$ & Age group $50-65$ years & $9.72(7.75)$ & 91.3 & 6.9 & 1.8 & \\
\hline & $N=351$ & Age group $>65$ years & $9.99(7.2)$ & 91.2 & 6.6 & 2.2 & \\
\hline \multirow{2}{*}{$\begin{array}{l}\text { Delhi } \\
\left(28.3^{\circ} \mathrm{N}\right)\end{array}$} & $N=1346$ & Adults, $\geq 50$ years, age $58(9.5)$ years, $48 \% \mathrm{M}, 52 \% \mathrm{~F}$ & $9.8(7.6)$ & 91.3 & 6.8 & 1.9 & \multirow{2}{*}{$\begin{array}{l}\text { Garg } \\
2013[88]\end{array}$} \\
\hline & $N=1829$ & Adolescents, $45 \% \mathrm{M}, 55 \% \mathrm{~F}$, age $13.3(2.5)$ years & $8.3(5.2)$ & 96.9 & 2.6 & 0.5 & \\
\hline \multirow[t]{3}{*}{$\begin{array}{l}\text { Delhi } \\
\left(28.3^{\circ} \mathrm{N}\right)\end{array}$} & $N=521$ & $\begin{array}{l}\text { Pregnant women, lower-middle income level, } \\
\text { age } 24.6(2.8) \text { years }\end{array}$ & $9.28(4.88)$ & 96.3 & - & - & \multirow[t]{3}{*}{$\begin{array}{l}\text { Marwaha } \\
2011[89]\end{array}$} \\
\hline & $N=342$ & $\begin{array}{l}\text { Lactating mothers, from the above group } 6-8 \text { weeks } \\
\text { postpartum. }\end{array}$ & $7.84(3.32)$ & 99.7 & - & - & \\
\hline & $N=342$ & Exclusively breastfed Infants & $8.92(4.2)$ & 98.8 & - & - & \\
\hline \multirow{2}{*}{$\begin{array}{l}\text { Delhi } \\
\left(28.3^{\circ} \mathrm{N}\right)\end{array}$} & $N=180$ & Lactating mothers & $10.88(5.8)$ & - & - & - & \multirow{2}{*}{$\begin{array}{l}\text { * Seth } \\
2009[90]\end{array}$} \\
\hline & $N=180$ & Exclusively breastfed infants, 2-24 weeks old & $11.56(8.3)$ & - & - & - & \\
\hline \multirow[t]{2}{*}{$\begin{array}{l}\text { Delhi } \\
\left(28.3^{\circ} \mathrm{N}\right)\end{array}$} & $N=26$ & $\begin{array}{l}\text { Infants, urban, age } 16 \pm 4.1 \text { months, } 15 \mathrm{M} / 11 \mathrm{~F} \text {, low } \\
\text { income families, high air pollution area }\end{array}$ & $12.4(7)$ & - & - & - & \multirow[t]{2}{*}{$\begin{array}{l}\text { Agarwal } \\
2002[63]\end{array}$} \\
\hline & $N=31$ & $\begin{array}{l}\text { Infants, urban, } 15.9 \text { (3.8) months, } 15 \mathrm{M} / 16 \mathrm{~F} \text {, low income } \\
\text { families, low air pollution area }\end{array}$ & $27.1(7)$ & - & - & - & \\
\hline
\end{tabular}


Table 1. Cont

\begin{tabular}{|c|c|c|c|c|c|c|c|}
\hline \multirow[b]{2}{*}{ Locale } & \multirow{2}{*}{\multicolumn{2}{|c|}{ Study Subjects }} & \multirow{3}{*}{$\begin{array}{c}\text { 25(OH)D } \\
\text { (ng/mL) Mean } \\
(\mathrm{SD}) \\
\end{array}$} & \multicolumn{3}{|c|}{ Vitamin D Status } & \multirow[b]{2}{*}{ Reference } \\
\hline & & & & $\%$ deficient & $\%$ insufficient & $\%$ sufficient & \\
\hline \multirow{5}{*}{$\begin{array}{l}\text { Delhi } \\
\left(28.3^{\circ} \mathrm{N}\right)\end{array}$} & & Urban slum children, age 9-30 months & & & & & \multirow{5}{*}{$\begin{array}{l}\text { Tiwari } \\
2004 \text { [91] }\end{array}$} \\
\hline & $N=47$ & Sundernagari area, winter & $38.52(10.28)$ & - & - & - & \\
\hline & $N=49$ & Rajiv Colony area, winter & $9.5(10.8)$ & - & - & - & \\
\hline & $N=48$ & Rajiv Colony area, summer & $7.12(8.96)$ & - & - & - & \\
\hline & $N=52$ & Gurgaon area, summer & $7.68(8.08)$ & - & - & - & \\
\hline \multirow{2}{*}{$\begin{array}{l}\text { Delhi } \\
\left(28.3^{\circ} \mathrm{N}\right)\end{array}$} & $N=60$ & Lactating mothers $25.0(2.0)$ years & $9.06(4.78)$ & 98.3 & - & - & \multirow{2}{*}{$\begin{array}{l}\text { Mehrotra } \\
2010[92]\end{array}$} \\
\hline & $N=60$ & Breastfed infants, $3.0(0.14)$ months & $9.03(4.63)$ & 100 & 0 & 0 & \\
\hline \multirow[t]{2}{*}{$\begin{array}{l}\text { Delhi } \\
\left(28.3^{\circ} \mathrm{N}\right)\end{array}$} & $N=98$ & Lactating mothers 23.1 (3.3) years & $\begin{array}{l}\text { Median } \\
9.8(5.0-13.8)\end{array}$ & - & - & - & \multirow[t]{2}{*}{$\begin{array}{l}\text { Jain } \\
2011 \text { [93] }\end{array}$} \\
\hline & $N=98$ & Breastfed infants, $58.2 \% \mathrm{M}$, age 13.6 (2.2)weeks & $\begin{array}{l}\text { Median } \\
10.1(2.5-17.1)\end{array}$ & - & - & - & \\
\hline \multirow[t]{6}{*}{$\begin{array}{l}\text { Delhi } \\
\left(28.3^{\circ} \mathrm{N}\right)\end{array}$} & $N=220$ & Infants, low birth-weight, at birth & $\begin{array}{l}\text { Median } \\
6.5(4.0-54.5) \\
\end{array}$ & 93 & - & - & \multirow[t]{6}{*}{$\begin{array}{l}\text { Agarwal } \\
2012[94]\end{array}$} \\
\hline & $N=127$ & Infants, low birth-weight, at 3 months & $\begin{array}{l}\text { Median } \\
11.1(4.0-78.0)\end{array}$ & 72.4 & - & - & \\
\hline & $N=116$ & Infants, normal birth-weight, at birth & $\begin{array}{l}\text { Median } \\
5.8(4.0-26.6) \\
\end{array}$ & 94.8 & - & - & \\
\hline & $N=77$ & Infants, normal birth-weight, at 3 months & $\begin{array}{l}\text { Median } \\
8.2(4-29.7) \\
\end{array}$ & 83.1 & - & - & \\
\hline & $N=216$ & Mothers of low birth-weight infants, at term & $\begin{array}{l}\text { Median 5.6 } \\
(4.0-38.3) \\
\end{array}$ & 93.5 & 4.2 & 2.3 & \\
\hline & $N=116$ & Mothers of normal birth-weight infants at term & $\begin{array}{l}\text { Median } \\
5.8(4.0-21.1)\end{array}$ & 96.6 & 1.7 & 1.7 & \\
\hline \multirow{2}{*}{$\begin{array}{l}\text { Delhi } \\
\left(28.3^{\circ} \mathrm{N}\right)\end{array}$} & $N=97$ & Urban, lactating mothers, low income level & $9.85(6.28)$ & - & - & - & \multirow{2}{*}{$\begin{array}{l}\text { Agarwal } \\
2010[95]\end{array}$} \\
\hline & $N=97$ & Exclusively breastfed infants, age 10 weeks & $12.59(8.37)$ & - & - & - & \\
\hline
\end{tabular}


Table 1. Cont.

\begin{tabular}{|c|c|c|c|c|c|c|c|}
\hline \multirow[b]{2}{*}{ Locale } & \multirow{2}{*}{\multicolumn{2}{|c|}{ Study Subjects }} & \multirow{2}{*}{$\begin{array}{l}25(O H) D \\
(n g / m L) \\
\text { Mean (SD) }\end{array}$} & \multicolumn{3}{|c|}{ Vitamin D Status } & \multirow[b]{2}{*}{ Reference } \\
\hline & & & & $\%$ deficient & $\%$ insufficient & $\%$ sufficient & \\
\hline $\begin{array}{l}\text { Lucknow, } \\
26.8^{\circ} \mathrm{N}\end{array}$ & $N=92$ & $\begin{array}{l}\text { Urban adults, } 67 \mathrm{~F}, 25 \mathrm{M} \text {, age } 34.2(6.7) \text { years, } \\
\text { hospital staff }\end{array}$ & $12.3(10.9)$ & 78.3 & - & - & $\begin{array}{l}\text { Arya } \\
2004[96]\end{array}$ \\
\hline \multirow[t]{4}{*}{$\begin{array}{l}\text { Lucknow } \\
\left(26.8^{\circ} \mathrm{N}\right)\end{array}$} & Total $N=207$ & $\begin{array}{l}\text { Pregnant women before labor, low and middle income } \\
\text { group, age } 24.0(4.1) \text { years. }\end{array}$ & $14(9.3)$ & - & - & - & \multirow[t]{4}{*}{$\begin{array}{l}\text { Sachan } \\
2005[97]\end{array}$} \\
\hline & $N=140$ & Urban F & $14.0(9.5)$ & - & - & - & \\
\hline & $N=67$ & Rural F & $14.1(8.9)$ & - & - & - & \\
\hline & $N=207$ & Neonates/cord blood & $8.4(5.7)$ & 95.7 & - & - & \\
\hline \multirow{6}{*}{$\begin{array}{l}\text { Barabanki } \\
32 \mathrm{~km} \text { from } \\
\text { Lucknow } \\
\left(27^{\circ} \mathrm{N}\right)\end{array}$} & $N=139$ & Rural pregnant women, age 26.7 (4.1) years & $15.12(7.92)$ & 74 & - & - & \multirow{6}{*}{$\begin{array}{l}\text { Sahu } \\
2009[98]\end{array}$} \\
\hline & $N=121$ & Rural F adolescents, age 14.3 (2.7) years. & $13.32(6.4)$ & 88.6 & - & - & \\
\hline & $N=28$ & sisters of 34 boys, age 14.4 (2.7) years, in winter & $12.52(5.4)$ & - & - & - & \\
\hline & $N=34$ & brothers of 28 girls, age 14 (3) years, in winter & $27(11.6)$ & - & - & - & \\
\hline & $N=260$ & Rural (pregnant women + girls) in summer & $22.2(7.92)$ & - & - & - & \\
\hline & $N=260$ & Rural (pregnant women + girls) in winter & $10.92(4.92)$ & - & - & - & \\
\hline $\begin{array}{l}\text { Varanasi } \\
\left(25.3^{\circ} \mathrm{N}\right) \\
\end{array}$ & $N=200$ & Adults, $M, \geq 50$ years, age $62.61(7.64)$ years & $18.96(10.23)$ & 58 & 28.5 & 13.5 & $\begin{array}{l}\text { Agarwal } \\
2013[99]\end{array}$ \\
\hline \multicolumn{8}{|c|}{ Southern India } \\
\hline \multirow{3}{*}{$\begin{array}{l}\text { Tirupati } \\
\left(13.4^{\circ} \mathrm{N}\right)\end{array}$} & Total $N=316$ & & - & 69.3 & - & - & \multirow{3}{*}{$\begin{array}{l}\text { Harinarayan } \\
2004[74]\end{array}$} \\
\hline & $N=191$ & Rural adults, age 44 (1.03) years & $21(0.46)$ & 58.6 & - & - & \\
\hline & $N=125$ & Urban adults, age $45.5(0.95)$ years & $13.52(0.59)$ & 85.6 & - & - & \\
\hline \multirow{5}{*}{$\begin{array}{l}\text { Tirupati } \\
\left(13.4^{\circ} \mathrm{N}\right)\end{array}$} & Total $N=1285$ & $21 \% \mathrm{M}, 79 \% \mathrm{~F}$ & - & - & - & - & \multirow{5}{*}{$\begin{array}{l}\text { Harinarayan } \\
2008[100]\end{array}$} \\
\hline & $N=205$ & Rural adults, age 43 years. $53 \% \mathrm{M}, 47 \% \mathrm{~F}$ & $\begin{array}{l}\text { M } 23.73(0.8) \\
\text { F19 }(0.89)\end{array}$ & $\begin{array}{l}\text { M } 44 \\
\text { F } 70\end{array}$ & $\begin{array}{l}\text { M } 39.5 \\
\text { F } 29\end{array}$ & $\begin{array}{l}\text { M } 16.5 \\
\text { F } 1\end{array}$ & \\
\hline & $N=941$ & $\begin{array}{l}\text { Urban adults, age } 46 \text { years. } 14 \% \mathrm{M}, 86 \% \mathrm{~F} \\
\text { Hospital staff \& relatives }\end{array}$ & $\begin{array}{l}\text { M } 18.54(0.8) \\
\text { F } 15.5(0.3)\end{array}$ & $\begin{array}{l}\text { M } 62 \\
\text { F 75 }\end{array}$ & $\begin{array}{l}\text { M } 26 \\
\text { F } 19\end{array}$ & $\begin{array}{l}\text { M } 12 \\
\text { F } 6\end{array}$ & \\
\hline & $N=70$ & Rural children, age 13 years. $48 \% \mathrm{M}, 52 \% \mathrm{~F}$ & $\begin{array}{l}\text { M } 17(1.3) \\
\text { F } 19(1.59)\end{array}$ & $\begin{array}{l}\text { M 76.5 } \\
\text { F 72.2 }\end{array}$ & $\begin{array}{l}\text { M } 14.7 \\
\text { F } 13.9\end{array}$ & $\begin{array}{l}\text { M } 8.8 \\
\text { F } 13.9 \\
\end{array}$ & \\
\hline & $N=69$ & Urban children, age 13 years. $43 \% \mathrm{M}, 57 \% \mathrm{~F}$ & $\begin{array}{l}\text { M 15.57(1.2) } \\
\text { F } 18.5(1.66)\end{array}$ & $\begin{array}{l}\text { M } 81.5 \\
\text { F } 62.9\end{array}$ & $\begin{array}{l}\text { M } 14.8 \\
\text { F } 25.7\end{array}$ & $\begin{array}{l}\text { M } 3.7 \\
\text { F } 11.4\end{array}$ & \\
\hline
\end{tabular}


Table 1. Cont.

\begin{tabular}{|c|c|c|c|c|c|c|c|}
\hline \multirow[b]{2}{*}{ Locale } & \multirow{2}{*}{\multicolumn{2}{|c|}{ Study Subjects }} & \multirow{2}{*}{$\begin{array}{c}25(\mathrm{OH}) \mathrm{D} \\
(\mathrm{ng} / \mathrm{mL}) \\
\text { Mean (SD) }\end{array}$} & \multicolumn{3}{|c|}{ Vitamin D Status } & \multirow[b]{2}{*}{ Reference } \\
\hline & & & & $\%$ deficient & $\%$ insufficient & $\%$ sufficient & \\
\hline $\begin{array}{l}\text { Tirupati } \\
\left(13.4^{\circ} \mathrm{N}\right)\end{array}$ & $N=164$ & Rural postmenopausal women, age 54 (8) years. & $14.6(7)$ & 82 & - & - & $\begin{array}{l}\text { Harinarayan } \\
2005[101]\end{array}$ \\
\hline $\begin{array}{l}\text { Tirupati } \\
\left(13.4^{\circ} \mathrm{N}\right)\end{array}$ & $N=150$ & Semi-urban postmenopausal women, age 60.1 (5.0) years & $20.85(8.63)$ & 50 & - & - & $\begin{array}{l}\text { Paul } \\
2008[102]\end{array}$ \\
\hline \multirow{3}{*}{$\begin{array}{l}\text { Tirupati } \\
\left(13.4^{\circ} \mathrm{N}\right)\end{array}$} & Total $N=191$ & Semi-urban women & - & - & - & - & \multirow{3}{*}{$\begin{array}{l}\text { Harinarayan } \\
2011[103]\end{array}$} \\
\hline & $N=55$ & Reproductive F age $37.42(0.72)$ years & $15.70(1.38)$ & 76.3 & 16.4 & 7.3 & \\
\hline & $N=136$ & Postmenopausal F, age $53.29(0.72)$ years. & $17.70(0.94)$ & 66.9 & 22.8 & 10.3 & \\
\hline $\begin{array}{l}\text { Mysore } \\
\left(12.3^{\circ} \mathrm{N}\right)\end{array}$ & $N=559$ & $\begin{array}{l}\text { Pregnant women at the } 30 \text { th week of pregnancy, } \\
\text { age } 24 \text { years. }\end{array}$ & $\begin{array}{l}\text { Median } 15.12 \\
(9.6-23.4)\end{array}$ & 66.5 & - & - & $\begin{array}{l}\text { Farrant } \\
2009[104]\end{array}$ \\
\hline \multicolumn{8}{|c|}{ Eastern India } \\
\hline $\begin{array}{l}\text { Kolkata } \\
\left(22.5^{\circ} \mathrm{N}\right)\end{array}$ & $N=40$ & Doctors, $39 \mathrm{M}, 1 \mathrm{~F}$, age 52.22 (10.91) years. & $13.02(4.77)$ & 92.5 & 5 & 2.5 & $\begin{array}{l}\text { Baidya } \\
2012[54]\end{array}$ \\
\hline \multicolumn{8}{|c|}{ Western India } \\
\hline \multirow[t]{3}{*}{$\begin{array}{l}\text { Mumbai } \\
\left(18.9^{\circ} \mathrm{N}\right)\end{array}$} & $N=42$ & $\begin{array}{l}\text { Pregnant women } 37 \text { th week of pregnancy, } \\
\text { age } 20-35 \text { years, middle income group }\end{array}$ & $22.99(10.93)$ & - & - & - & \multirow[t]{3}{*}{$\begin{array}{l}\text { Bhalala } \\
2007[105]\end{array}$} \\
\hline & $N=42$ & Cord blood/neonates & $19.36(9.57)$ & - & - & - & \\
\hline & $N=35$ & Infants, 3 months old, exclusively breastfed & $18.19(9.74)$ & - & - & - & \\
\hline \multirow{3}{*}{$\begin{array}{l}\text { Mumbai } \\
\left(18.9^{\circ} \mathrm{N}\right)\end{array}$} & Total $N=214$ & Urban adults, $81 \% \mathrm{M}, 19 \% \mathrm{~F}$, age $26-30$ years. & - & 87.5 & - & - & \multirow{3}{*}{$\begin{array}{l}\text { Multani } \\
2010[58]\end{array}$} \\
\hline & $N=174$ & M, Resident doctors & $12.80(7.94)$ & 85 & - & - & \\
\hline & $N=40$ & F, Resident doctors & $10.94(4.54)$ & 97.5 & - & - & \\
\hline \multirow{3}{*}{$\begin{array}{l}\text { Mumbai } \\
\left(18.9^{\circ} \mathrm{N}\right)\end{array}$} & Total $N=1137$ & Young urban adults, age 30.38 (3.55) years & $17.4(9.1)$ & - & - & 7.2 & \multirow{3}{*}{$\begin{array}{l}\text { Shivane } \\
2011[106]\end{array}$} \\
\hline & $N=558$ & $\mathrm{M}$ & $18.9(8.9)$ & - & - & 9.7 & \\
\hline & $N=579$ & $\mathrm{~F}$ & $15.8(9.1)$ & - & - & 4.8 & \\
\hline
\end{tabular}


Table 1. Cont.

\begin{tabular}{|c|c|c|c|c|c|c|c|}
\hline \multirow[b]{2}{*}{ Locale } & \multirow{2}{*}{\multicolumn{2}{|c|}{ Study Subjects }} & \multirow{2}{*}{$\begin{array}{c}25(\mathrm{OH}) \mathrm{D} \\
(\mathrm{ng} / \mathrm{mL}) \\
\operatorname{Mean}(\mathrm{SD})\end{array}$} & \multicolumn{3}{|c|}{ Vitamin D Status } & \multirow[b]{2}{*}{ Reference } \\
\hline & & & & $\%$ deficient & $\%$ insufficient & $\%$ sufficient & \\
\hline \multirow{3}{*}{$\begin{array}{l}\text { Pune } \\
\left(18.5^{\circ} \mathrm{N}\right)\end{array}$} & $N=110$ & Slum toddlers, age $2.6(0.7)$ years & - & - & - & - & \multirow{3}{*}{$\begin{array}{l}\text { Ekbote } \\
2010[107]\end{array}$} \\
\hline & $N=50$ & $\begin{array}{l}25 \mathrm{M}, 25 \mathrm{~F} \text {, outdoors (daily sun exposure of } 15-60 \mathrm{~min} \text { or } \\
\text { more) }\end{array}$ & $45.24(31.88)$ & - & - & - & \\
\hline & $N=60$ & $31 \mathrm{M}, 29 \mathrm{~F}$, indoors & $3.84(10.64)$ & - & - & - & \\
\hline $\begin{array}{l}\text { Pune } \\
\left(18.5^{\circ} \mathrm{N}\right)\end{array}$ & $N=71$ & $\begin{array}{l}\text { Urban children, } 36 \mathrm{M}, 35 \mathrm{~F} \text {, age } 2.8(0.6) \text { years, all income } \\
\text { groups }\end{array}$ & $11.94(12.61)$ & - & - & - & $\begin{array}{l}\text { Ekbote } \\
2011[108]\end{array}$ \\
\hline $\begin{array}{l}\text { Pune } \\
\left(18.5^{\circ} \mathrm{N}\right)\end{array}$ & $N=50$ & Adolescent girls, low income group, age $14.7(0.10)$ years & $\begin{array}{l}\text { Median } 9.36 \\
(5.4-12.76)\end{array}$ & - & - & - & $\begin{array}{l}\text { Khadilkar } \\
2010[109]\end{array}$ \\
\hline \multirow{3}{*}{$\begin{array}{l}\text { Pune } \\
\left(18.5^{\circ} \mathrm{N}\right)\end{array}$} & & Women: housewives, working women, retired & - & - & - & - & \multirow{3}{*}{$\begin{array}{l}\text { Kadam } \\
2010[110]\end{array}$} \\
\hline & $N=80$ & Premenopausal F, age 45.6 (4.8) years & $9.68(4.56)$ & - & - & - & \\
\hline & $N=92$ & Postmenopausal F, age 54.0 (7.1) years. & $10.76(6.8)$ & - & - & - & \\
\hline \multirow{3}{*}{$\begin{array}{l}\text { Pune } \\
\left(18.5^{\circ} \mathrm{N}\right)\end{array}$} & Total $N=214$ & Premenarchal school girls, low income group & $24.6(10.4)$ & 34.2 & - & - & \multirow{3}{*}{$\begin{array}{l}\text { Kadam } \\
2011[111]\end{array}$} \\
\hline & $N=134$ & Age $8-9$ years & $24.36(10.32)$ & - & - & - & \\
\hline & $N=80$ & Age $10-12$ years & $25.12(10.64)$ & - & - & - & \\
\hline \multicolumn{8}{|c|}{ All over India } \\
\hline \multirow{2}{*}{$\begin{array}{l}18 \text { cities } \\
\text { spread all } \\
\text { over India }\end{array}$} & $N=2119$ & $\begin{array}{l}\text { Adults, medical and paramedical personnel, } 72 \% \mathrm{M}, 28 \% \\
\text { F, age } 42.71 \text { (6.8) years. }\end{array}$ & $14.35(10.62)$ & 79 & 15 & 6 & \multirow[t]{2}{*}{$\begin{array}{l}\text { Beloyartseva } \\
2012[59]\end{array}$} \\
\hline & & No significant differences were found either between men a & d women, or nc & hern and south & rn India. & & \\
\hline
\end{tabular}


Table 2. Vitamin D status and its correlation with bone mineral density (BMD) in ostensibly healthy Indians. For additional details of vitamin D status, see Table 1. All 25(OH)D values have been shown in $\mathrm{ng} / \mathrm{mL}$. To convert from $\mathrm{nM}$ to $\mathrm{ng} / \mathrm{mL}$, $\mathrm{nM}$ values were divided by (2.5). Vitamin D deficiency is defined as $25(\mathrm{OH}) \mathrm{D}<20 \mathrm{ng} / \mathrm{mL}$. DEXA is Dual Energy X-ray Absorptiometry. Age of the subjects is in mean age (SD) years, unless otherwise indicated.

\begin{tabular}{|c|c|c|c|c|}
\hline Locale & & Study Subjects & BMD Measured by DEXA as Mean (SD) $\mathrm{gm} / \mathrm{cm}^{2}$ & Reference \\
\hline \multicolumn{5}{|c|}{ Vitamin D status correlated positively with BMD: } \\
\hline \multirow[t]{5}{*}{$\begin{array}{l}\text { Varanasi } \\
\left(25.3^{\circ} \mathrm{N}\right)\end{array}$} & $N=200$ & $\begin{array}{l}\text { Adults, } M, \geq 50 \text { years, } \\
\text { age } 62.61(7.64) \text { years, } \\
58 \% \text { subjects were } \\
\text { vitamin D deficient. }\end{array}$ & $\begin{array}{l}\text { At right femoral neck, } 42 \% \text { subjects had osteopenia and } 8.5 \% \text { had osteoporosis. At trochanter of right } \\
\text { femur, } 37 \% \text { had osteopenia and } 7.5 \% \text { had osteoporosis. At right hip } 41 \% \text { subjects had osteopenia and } \\
7 \% \text { had osteoporosis. } \\
\text { Mean T scores of the subjects (right femur): Neck }=-0.92(1.22) \text {, Trochanter }=-0.59(1.41) \text { and } \\
\text { Total hip }=-0.55(1.37) \text {. T score }=(\text { subject's BMD-young adult mean BMD) } /(1 \mathrm{SD} \text { of adult } \\
\text { mean BMD) or normal BMD. }\end{array}$ & \multirow[t]{5}{*}{$\begin{array}{l}\text { Agarwal } \\
2013 \text { [99] }\end{array}$} \\
\hline & & $25(\mathrm{OH}) \mathrm{D}$ level $>22 \mathrm{ng} / \mathrm{mL}$ & normal mean BMD at femur neck, trochanter, and total hip & \\
\hline & & $25(\mathrm{OH}) \mathrm{D}<10 \mathrm{ng} / \mathrm{mL}$ & osteoporosis at femur neck and trochanter & \\
\hline & & $25(\mathrm{OH})>15 \mathrm{ng} / \mathrm{mL}$ & osteopenia at femur neck and total hip & \\
\hline & & $25(\mathrm{OH})>16 \mathrm{ng} / \mathrm{mL}$ & osteopenia at trochanter & \\
\hline \multicolumn{5}{|c|}{ Vitamin D status correlated positively with BMD, but not at all the sites studied: } \\
\hline $\begin{array}{l}\text { Lucknow, } \\
26.8^{\circ} \mathrm{N}\end{array}$ & $N=92$ & $\begin{array}{l}\text { Urban adults, M } 25, \mathrm{~F} 67, \\
78.3 \% \text { subjects were vitamin } \\
\text { D deficient. }\end{array}$ & $\begin{array}{l}\text { BMD of the spine, femur (neck, trochanter, inter-trochanter and Wards' triangle regions) and forearm } \\
\text { (distal, mid and ultradistal regions) was lower compared with Caucasians. } 25(\mathrm{OH}) \mathrm{D} \text { levels correlated } \\
\text { with BMD at the femoral neck ( } r=0.46, p=0.037) \text { and Ward's triangle only. }(r=0.50, p=0.020)\end{array}$ & $\begin{array}{l}\text { Arya } \\
2004 \text { [96] }\end{array}$ \\
\hline \multirow[t]{3}{*}{$\begin{array}{l}\text { Delhi } \\
\left(28.3^{\circ} \mathrm{N}\right)\end{array}$} & $\begin{array}{l}\text { Total } \\
N=105\end{array}$ & $\begin{array}{l}\text { Urban adults, } 51 \mathrm{M} \text { and } 54 \mathrm{~F} \text {, } \\
\text { age } 43.3(9.7) \text { years. } 94.3 \% \\
\text { subjects were vitamin D } \\
\text { deficient. }\end{array}$ & 25(OH)D levels correlated with BMD at hip, but not at lumbar spine or forearm. & \multirow[t]{3}{*}{$\begin{array}{l}\text { Vupputuri } \\
2006[83]\end{array}$} \\
\hline & $N=41$ & $25(\mathrm{OH}) \mathrm{D}>9.0 \mathrm{ng} / \mathrm{mL}$ & BMD at the hip $=0.893(0.114)$ was higher than of those at $25(\mathrm{OH}) \mathrm{D} \leq 9.0 \mathrm{ng} / \mathrm{mL}(p=0.001)$ & \\
\hline & $N=64$ & $25(\mathrm{OH}) \mathrm{D} \leq 9.0 \mathrm{ng} / \mathrm{mL}$ & BMD at the hip $=0.839(0.112)$ & \\
\hline
\end{tabular}


Table 2. Cont

\begin{tabular}{|c|c|c|c|c|}
\hline Locale & & Study Subjects & BMD Measured by DEXA as Mean (SD) $\mathrm{gm} / \mathrm{cm}^{2}$ & Reference \\
\hline \multicolumn{5}{|c|}{ Vitamin D status did not correlate with BMD: } \\
\hline $\begin{array}{l}\text { Punjab } \\
\left(31.1^{\circ} \mathrm{N}\right) \\
\& \\
\text { Haryana } \\
\left(29^{\circ} \mathrm{N}\right)\end{array}$ & $N=42$ & $\begin{array}{l}\text { Adults, age } 20-30 \text { years, } \\
20 \mathrm{M}, 22 \mathrm{~F} \text {, paramilitary } \\
\text { soldiers. Adequate diet, sun } \\
\text { exposure and physical } \\
\text { exercise. }\end{array}$ & $\begin{array}{l}\text { Individual BMD data with peak bone mass in white Caucasians revealed that among Indian men, } \\
\text { osteopenia was noted in } 50 \% \text { at the lumbar spine, } 35 \% \text { at the hip and } 50 \% \text { at the forearm. } 10 \% \text { of men } \\
\text { had osteoporosis of the lumbar spine. Among women, osteopenia was noted in } 32 \% \text { at the lumbar spine, } \\
14 \% \text { at the hip and } 21 \% \text { at the forearm. In men, mean BMD was significantly lower when compared to } \\
\text { Caucasians at the lumbar spine only. Indian men }=0.947(0.086) v \text { s. Caucasian controls }=1.091(0.110) \text {, } \\
p=0.0004 \text {. }\end{array}$ & $\begin{array}{l}\text { Tandon } \\
2003[56]\end{array}$ \\
\hline $\begin{array}{l}\text { Delhi } \\
\left(28.3^{\circ} \mathrm{N}\right)\end{array}$ & $N=664$ & $\begin{array}{l}\text { Urban adolescent } \mathrm{F} \text {, school } \\
\text { girls, age } 12.8(2.7) \text { years. } \\
\text { Lower income level } N=369 \\
\text { and Higher income level } \\
N=295\end{array}$ & $\begin{array}{l}\text { The upper income level girls were significantly taller and weighed more. They also had higher BMD in } \\
\text { distal forearm and calcanium.BMD forearm }\left(\mathrm{g} / \mathrm{cm}^{2}\right) \text { : lower income level } 0.337(0.070) \text { and upper } \\
\text { income level } 0.366(0.075) \text {. BMD calcaneum }\left(\mathrm{g} / \mathrm{cm}^{2}\right) \text { : lower income level } 0.407(0.073) \text { and upper } \\
\text { income level } 0.464(0.093) \text {. }\end{array}$ & $\begin{array}{l}\text { Marwaha } \\
2007[86]\end{array}$ \\
\hline $\begin{array}{l}\text { Delhi } \\
\left(28.3^{\circ} \mathrm{N}\right)\end{array}$ & $N=5137$ & $\begin{array}{l}\text { Urban adolescents and } \\
\text { school children, age 10-18 } \\
\text { years. } 92.6 \% \text { children from } \\
\text { lower income level ( } N= \\
3089 \text { ) and } 84.9 \% \text { children } \\
\text { from upper income level ( } N \\
=2048) \text { were vitamin D } \\
\text { deficient. }\end{array}$ & $\begin{array}{l}\text { BMD was evaluated in } 555 \text { children. Children in the lower income level group had significantly lower } \\
\text { BMD values at the forearm than did those in the upper income level group. Only BMD of age group } \\
(10-12) \text { years is mentioned in this review. Boys, lower income level }=0.313(0.044),(N=27) \text {; boys, } \\
\text { upper income level }=0.387(0.146),(N=24) \text {; girls, lower income level }=0.297(0.048),(N=70) \text { and } \\
\text { girls upper income level }=0.345(0.054),(N=39) \text {. }\end{array}$ & $\begin{array}{l}\text { Marwaha } \\
2005[85]\end{array}$ \\
\hline $\begin{array}{l}\text { Delhi } \\
\left(28.3^{\circ} \mathrm{N}\right)\end{array}$ & $N=1600$ & $\begin{array}{l}\text { Urban adults }(\mathrm{M} 49.5 \% \\
\text { F } 50.5 \%) \text {, age }>50 \text { years. } \\
91.2 \% \text { subjects were } \\
\text { vitamin D deficient. }\end{array}$ & $\begin{array}{l}35.1 \% \text { subjects ( } \mathrm{M} 24.6 \% \text { and } \mathrm{F} 42.5 \% \text { ) had osteoporosis and } \\
49.5 \% \text { (M } 54.3 \% \text {, F } 44.9 \% \text { ) had osteopenia. }\end{array}$ & $\begin{array}{l}\text { Marwaha } \\
2011[112]\end{array}$ \\
\hline $\begin{array}{l}\text { Delhi } \\
\left(28.3^{\circ} \mathrm{N}\right)\end{array}$ & $\begin{array}{l}\text { Total } \\
N=186\end{array}$ & $\begin{array}{l}\text { Young urban college women, } \\
\text { age } 18.6(1.3) \text { years. } 96 \text { were } \\
\text { college girls (control group) } \\
\text { and } 90 \text { were sportswomen. }\end{array}$ & $\begin{array}{l}\text { With the exception of femur neck, higher BMD was noted in sportswomen by } 5,13.1,10.3 \text {, } \\
\text { and } 9.2 \% \text { in total body, total hip, forearm and lumbar spine and } 33 \% \text { radius, respectively. }\end{array}$ & $\begin{array}{l}\text { Marwaha } \\
2011 \text { [57] }\end{array}$ \\
\hline
\end{tabular}


Table 2. Cont.

\begin{tabular}{|c|c|c|c|c|}
\hline Locale & & Study Subjects & BMD Measured by DEXA as Mean (SD) $\mathrm{gm} / \mathrm{cm}^{2}$ & Reference \\
\hline $\begin{array}{l}\text { Tirupati } \\
\left(13.4^{\circ} \mathrm{N}\right)\end{array}$ & $\begin{array}{l}\text { Total } \\
N=149\end{array}$ & $\begin{array}{l}\text { Semi-urban women. } 82.5 \% \\
\text { out of } 40 \text { premenopausal } \\
\text { and } 67.8 \% \text { out of } 109 \\
\text { postmenopausal women were } \\
\text { vitamin D deficient. }\end{array}$ & $\begin{array}{l}\text { Comparatively, postmenopausal women had lower BMD in forearm, hip and lumbar spine. Osteoporosis } \\
\text { was seen at hip ( } 15 \% \text { and } 28 \%) \text {, forearm }(0 \% \text { and } 11 \%) \text {, lumbar spine } \\
\text { antero-posterior ( } 6 \% \text { and } 22 \%) \text { and lumbar spine lateral }(0 \% \text { and } 23 \%) \text { among premenopausal and } \\
\text { postmenopausal, respectively. }\end{array}$ & $\begin{array}{l}\text { Harinarayan } \\
2011[103]\end{array}$ \\
\hline \multirow[t]{4}{*}{$\begin{array}{l}\text { Tirupati } \\
\left(13.4^{\circ} \mathrm{N}\right)\end{array}$} & $N=150$ & $\begin{array}{l}\text { Semi-urban postmenopausal } \\
\text { women, age } 60.1(5) \text { years. } \\
50 \% \text { women were vitamin D } \\
\text { deficient. }\end{array}$ & $\begin{array}{l}\text { Osteoporosis was noted at lumbar spine in } 48 \% \text { women, at femoral neck in } 16.7 \% \text { women } \\
\text { BMD: lumbar spine }(\mathrm{LS})=0.798 \pm 0.142 \text {, femoral neck }=0.675 \pm 0.108\end{array}$ & \multirow[t]{4}{*}{$\begin{array}{l}\text { Paul } \\
2008[102]\end{array}$} \\
\hline & $N=74$ & $25(\mathrm{OH}) \mathrm{D}(>20 \mathrm{ng} / \mathrm{mL})$ & BMD: lumbar spine $=0.816($ no SD), femoral neck $=0.694$ (no SD) & \\
\hline & $N=59$ & 25(OH)D (10-20 ng/mL) & BMD: lumbar spine $=0.780$ (no SD), femoral neck $=0.657$ (no SD) & \\
\hline & $N=14$ & $25(\mathrm{OH}) \mathrm{D}(5-10 \mathrm{ng} / \mathrm{mL})$ & BMD: lumbar spine $=0.733(0.151)$, femoral neck $=0.649(0.102)$ & \\
\hline $\begin{array}{l}\text { Mumbai } \\
\left(18.9^{\circ} \mathrm{N}\right)\end{array}$ & $N=214$ & $\begin{array}{l}\text { Resident doctors M } 81.3 \% \text {, } \\
\text { F } 18.7 \% \text {, age } 26-30 \text { years. } \\
87.5 \% \text { subjects were vitamin } \\
\text { D deficient. }\end{array}$ & $59.7 \%$ men and $67.5 \%$ women had osteopenia. $18.39 \%$ men and $12.5 \%$ women had osteoporosis. & $\begin{array}{l}\text { Multani } \\
2010[58]\end{array}$ \\
\hline $\begin{array}{l}\text { Pune } \\
\left(18.5^{\circ} \mathrm{N}\right)\end{array}$ & $N=50$ & $\begin{array}{l}\text { Adolescent girls, low income } \\
\text { group, age } 14.7(0.10) \text { years. }\end{array}$ & $\begin{array}{l}\text { Pune girls had lower bone area and bone mineral content, (i.e., shorter and lighter girls) compared to UK } \\
\text { South Asian and UK Caucasian girls. }\end{array}$ & $\begin{array}{l}\text { Khadilkar } \\
2010[109]\end{array}$ \\
\hline $\begin{array}{l}\text { Pune } \\
\left(18.5^{\circ} \mathrm{N}\right)\end{array}$ & $N=172$ & $\begin{array}{l}\text { Semi-urban women. } \\
\text { Premenopausal } N=80, \\
\text { and postmenopausal } N=92 \text {. }\end{array}$ & $\begin{array}{l}\text { Comparatively, postmenopausal women had lower BMD in femoral neck, total hip and lumbar spine. } \\
\text { Prevalence of osteoporosis at lumbar spine was observed in } 25.8 \% \text { of postmenopausal women and } 7.6 \% \\
\text { of pre-menopausal women. Prevalence of osteopenia was observed in } 48.4 \% \text { of post-menopausal and } \\
44.3 \% \text { of premenopausal women. }\end{array}$ & $\begin{array}{l}\text { Kadam } \\
2010[110]\end{array}$ \\
\hline
\end{tabular}




\section{Genetic and Epigenetic Factors Affecting Vitamin D Status}

Genetic factors leading to vitamin D deficiency in Indians, due to their effect on expression of genes that modulate vitamin D metabolism may not be ruled out. Genetic factors such as polymorphisms in 7 dehydroxylase reductase, DBP, 1 alpha hydroxylase, VDR, 25 hydroxylase, 24 hydroxylase have been studied. However, a clear association between these polymorphisms and vitamin D status is yet to be established [113-115]. Epigenetic factors too may be important in this context. Epigenetic factors pertain to heritable changes in the gene expression, while the DNA sequence is unchanged. These are several possibilities - post-translational modifications of histones - methylation, acetylation and phosphorylation, and also aberrant expression of microRNAs. Interaction between genetic and environmental factors, modulated by epigenetic factors has been reported. $1 \alpha$ hydroxylase and 24 hydroxylase have been shown to be epigenetically controlled. Information regarding association between genetic and/or epigenetic factors and vitamin D status is inconclusive and warrants further study [116].

\section{Population Based Approaches to Improve Vitamin D Status in India: Supplementation, Food Fortification and Educational Programs}

There is protracted debate ongoing on issues pertaining optimal levels of intake of vitamin D, preferred form of vitamin D for human use and extraskeletal benefits of vitamin D. However, one thing is clear-Indians need more vitamin D. Vitamin D can be obtained from three sources: sun exposure (limitations of which has been discussed earlier), vitamin D supplements and vitamin D fortified foods. There is urgent need to prioritize development of national level programs to make available, quality-regulated and affordable vitamin D supplements and vitamin D fortified foods to the Indian populace. Very importantly, the government needs to implement measures to educate the Indian populace about the current status of vitamin D in India and also the modes to attain vitamin D sufficiency.

\section{Vitamin D Supplements Available in India}

Information was collected from 10 pharmacists, from an upper middleclass locality of Delhi. Supplements commonly available are- $\mathrm{D}_{3}$ (cholecalciferol), $1,25(\mathrm{OH})_{2} \mathrm{D}_{3}$ and 1 alpha hydroxy vitamin $\mathrm{D}_{3}$ (alfacalcidol). Some formulations have calcium too. Multivitamin formulations are also available and contain about $400 \mathrm{IU}$ of $\mathrm{D}_{3}$. None of the pharmacists had heard of $\mathrm{D}_{2}$ supplements. $\mathrm{D}_{3}$ supplement of $60,000 \mathrm{IU}$ is the highest selling one and is available in powder form in sachets or as oil-based capsules. Recommended dose on the label is once per week. The sachets indicate that half a sachet per week may also be taken. According to some pharmacists, many clinicians recommended 1 sachet daily for 10 days, followed by 1 sachet/week for 5-6 weeks to 1 sachet/week forever. The other vitamin D supplements mentioned here are present in lower doses ( $0.25 \mu \mathrm{g}$ or $500 \mathrm{IU})$ and daily intake (1-4 times/day) may be recommended by the clinicians. Calcium supplementation is generally recommended with vitamin $\mathrm{D}$ intake.

The cost of a single dose of 60,000 IU of vitamin $\mathrm{D}_{3}$ is about INR 30. Intake of 60,000 IU of vitamin $\mathrm{D}_{3}$ per week may be advisable for a short duration, for patients with severe vitamin $\mathrm{D}$ deficiency, but a regular weekly dose may be lead to toxicity problems. A lower dose of vitamin D not 
exceeding the limit of 4000 IU per day would be advisable for otherwise healthy individuals. This will also reduce the cost of the supplement and become more affordable to the common people of India.

Purchase of most drugs in India does not require a prescription. Additionally, more often than not pharmacists (commonly called "Chemists" in India) often claim to have all the information needed to prescribe medicines. Other than for acute health problems most socioeconomically backward people go directly to the pharmacist, more often than not, in order to save consultation fee of a licensed clinician. Pharmacists boldly recommended and sell medications to patients and often recommend a longer duration of medications to boost their sales. It is not uncommon for active vitamin D analogs such as calcitriol or 1-alpha D to be wrongfully prescribed by physicians and pharmacists in lieu of nutritional vitamin D supplements, thus putting unsuspecting patients at grave risk of hypercalcemia and if taken long-term possibly vascular calcification and kidney stones. In this context, it is very important that the along with the clinicians, pharmacists also be educated about toxicity issued related with vitamin D.

\section{Vitamin D Supplementation Studies in Ostensibly Healthy Indians}

Vitamin D supplementation studies in ostensibly healthy were compiled (Table 3). Supplementation resulted in significant improvement in vitamin D status, but a large proportion of the population had still did not attain sufficiency. The following study is noteworthy. In India, physicians often prescribe $\mathrm{D}_{3}$ 60,000 IU per week for 8 weeks for vitamin D deficiency. Twenty two healthy Indians with subnormal serum 25(OH)D levels were supplemented with oral $\mathrm{D}_{3} 60,000 \mathrm{IU} /$ week and calcium $1 \mathrm{gm} /$ day for 8 weeks. At 8 weeks the mean 25(OH)D levels increased from $10.16(3.96) \mathrm{ng} / \mathrm{mL}$ to $22.4(6.8) \mathrm{ng} / \mathrm{mL}$ and serum PTH normalized in all. Twenty two of the 23 subjects had 25(OH)D levels $>20 \mathrm{ng} / \mathrm{mL}$. At the end of 12 months however, all the subjects were vitamin D deficient, once again. To sustain optimal 25(OH)D levels vitamin D supplementation would need to be ongoing after the initial loading [117].

Some supplementation studies, in ostensibly healthy adolescents and adult subjects, resulted in improved bone health. These are tabulated separately (Table 4).

More frequent and lower doses, not exceeding $4000 \mathrm{IU} /$ day of vitamin D supplementation may be better for maintenance of serum 25(OH)D level. Most of the studies from India mention vitamin D status in terms serum 25(OH)D levels as below or above $20 \mathrm{ng} / \mathrm{mL}$ (or $50 \mathrm{nmol} / \mathrm{L}$ ). However, one must not lose sight of the fact that the aim of all interventions in terms of vitamin $\mathrm{D}$ status should be $\geq 30 \mathrm{ng} / \mathrm{mL}$ or above to derive both skeletal and extraskeletal benefits of this D-lightful nutrient [118], but with a precautionary stance to not exceed $100 \mathrm{ng} / \mathrm{mL}$.

\section{Vitamin D Fortification in USA and Canada}

Despite predominantly non-vegetarian dietary pattern, approximately $60 \%$ of the intake of vitamin D from food comes from fortified foods in USA [119] and Canada [120]. In USA, vitamin D fortification of foods is voluntary, but it is strictly regulated pertaining categories of foods, functional use and level of use, thus limiting over-fortification. Vitamin D fortified milk has been available in USA since the 1930s. Vitamin D is added to most milk sold in the United States, although it is not added to all milk products like cheese and ice cream. Some manufacturers also add it to cereal, soy 
milk, rice milk, and orange juice, usually along with calcium. In USA either form, $\mathrm{D}_{2}$ or $\mathrm{D}_{3}$, may be used for fortification, but commonly $\mathrm{D}_{3}$ is used. In Canada, the law mandates fortification of milk, milk alternatives and margarine. Similar to USA, for other permitted foods, vitamin D fortification D is voluntary, but fortification level is limited [121].

\section{Need for Vitamin D Fortified Food Products in India}

Vitamin D sufficiency via sun exposure is untenable for most Indians, as discussed earlier. Vitamin D (relatively) rich dietary sources are unaffordable and mostly limited, especially for vegetarians. Most Indians are vegetarians. Vitamin D supplements are unaffordable and not feasible as a population based approach. Fortification of widely consumed staple foods with vitamin D is the only viable solution towards attaining vitamin D deficiency in India. Unlike supplementation strategies, fortification of food with vitamin D poses a negligible risk of toxicity.

\section{Feasibility of Fortification of Foods with Vitamin D in India}

Food fortification is a much more economically viable approach compared to vitamin D supplementation. While the cost of fortified food items will be more than unfortified foods, it will be lower than supplementation.

1. Adaptability to fortified food by the consumers is much better than to supplementation. Food fortification requires relatively less change in food habits and preferences, leading to better efficacy of fortification programs, lowered cost to the consumer and a larger profit to the food manufacturers. Clearly a win-win partnership for all.

2. Food fortification may be a better choice compared to supplementation strategies, especially when targeting those who need it the most-women (including non-pregnant, pregnant and lactating), infants, children (especially girls, who are sidelined, more often than not, in India) and senior citizens.

3. Use of staple foods such as chapati flour, rice, etc., for fortification may have certain advantages over other fortification matrices. Indian government offers cereals, chapati flour, rice, lentils, etc., at subsidized rates to the socioeconomically underprivileged citizens. Additionally, cost of these products is generally tightly regulated by the government. Thus, no large fluctuations are observed in the cost of these food items in the open market also. This will ensure continued consumption of these foods fortified with vitamin D, by those who avail of them and result in better and sustained economical feasibility of the fortification programs in the long run.

4. Two vitamin D fortification studies in ostensibly healthy subjects were reported in the literature (see Table 5). Underprivileged toddlers, fed with fortified laddoos, resulted in significant increase in serum calcium and vitamin D levels and also in total body less head (TBLH) bone mineral content (BMC) [122]. The cost of fortified laddoo was INR 20 per laddoo, which may be prohibitive in itself. More cost effective food items could be fortified with vitamin D. In another study, 776 subjects (boys and girls) were given fortified milk, which resulted in significant improvement in their vitamin D status [123]. These results support the strategy of fortification of foods in India for redressing malnutrition problems in India. 
Table 3. Vitamin D supplementation studies in ostensibly healthy Indians. All 25(OH)D values have been shown in ng/mL. To convert from $\mathrm{nM}$ to $\mathrm{ng} / \mathrm{mL}, \mathrm{nM}$ values were divided by (2.5). Vitamin D deficiency is defined as $25(\mathrm{OH}) \mathrm{D}<20 \mathrm{ng} / \mathrm{mL}$, insufficiency as $20-29 \mathrm{ng} / \mathrm{mL}$ and sufficiency as $\geq 30 \mathrm{ng} / \mathrm{mL}$. ${ }^{\star}$ Information available from the abstract of the article. $\mathrm{D}_{3}$ is cholecalciferol. Calcium amount mentioned is of elemental calcium. Age of the subjects is in mean age (SD) years, unless otherwise indicated.

\begin{tabular}{|c|c|c|c|c|c|c|}
\hline \multirow{3}{*}{ Locale } & \multirow{3}{*}{ Study Subjects and Supplementation Protocols } & \multicolumn{4}{|c|}{ Vitamin D Status } & \multirow{3}{*}{ Reference } \\
\hline & & \multicolumn{2}{|c|}{ Before } & \multicolumn{2}{|c|}{ After } & \\
\hline & & $\begin{array}{c}25(\mathrm{OH}) \mathrm{D} \\
\text { Mean (SD) }\end{array}$ & $\begin{array}{c}\text { 25(OH)D } \\
\text { Mean (SD) }\end{array}$ & $\begin{array}{c}25(\mathrm{OH}) \mathrm{D} \\
\text { Mean (SD) }\end{array}$ & $\%$ Deficient & \\
\hline \multirow{4}{*}{$\begin{array}{l}\text { Barabanki, } 32 \mathrm{~km} \\
\text { from Lucknow } \\
\left(27^{\circ} \mathrm{N}\right)\end{array}$} & $\begin{array}{l}\text { Total } N=84 \text {, Rural pregnant women, low income } \\
\text { group, all received } 1 \text { gm calcium/day }\end{array}$ & $\begin{array}{c}\text { Median } 12.92 \\
(9.12-20.04)\end{array}$ & - & - & - & \multirow[t]{4}{*}{$\begin{array}{c}\text { Sahu } \\
2009[124]\end{array}$} \\
\hline & $N=14$, Control group & $\begin{array}{c}\text { Median } 10.32 \\
(7.56-12.28)\end{array}$ & - & $\begin{array}{l}\text { Median } 9.52 \\
(6.88-13.04)\end{array}$ & - & \\
\hline & $\begin{array}{l}N=35, \text { Group A, } 60,000 \mathrm{IU} \mathrm{D}_{3} \text { in } \\
\text { the } 5 \text { th gestational month }\end{array}$ & $\begin{array}{c}\text { Median } 13.26 \\
(9.04-19.08)\end{array}$ & - & $\begin{array}{c}\text { Median } 12.36 \\
(9.92-19.24)\end{array}$ & - & \\
\hline & $\begin{array}{l}N=35 \text {, Group } \mathrm{B}, 120,000 \mathrm{IU} \mathrm{D}_{3} \text { in the } 5 \text { th and } 7 \text { th } \\
\text { gestational month }\end{array}$ & $\begin{array}{l}\text { Median } 16.04 \\
(10.76-23.36)\end{array}$ & - & $\begin{array}{l}\text { Median } 21.36 \\
(16.46-35.02)\end{array}$ & - & \\
\hline \multirow[t]{7}{*}{$\begin{array}{l}\text { Lucknow } \\
\left(26.8^{\circ} \mathrm{N}\right)\end{array}$} & $\begin{array}{l}\text { Pregnant women and neonates. Women age } \\
26.7 \text { (4.0) years, low and middle income group. } \\
\text { All were prescribed } 1 \mathrm{gm} \text { calcium/day }\end{array}$ & - & - & (2) & - & \multirow[t]{7}{*}{$\begin{array}{c}\text { Kalra } \\
2012[125]\end{array}$} \\
\hline & $N=48$, Control group & - & & $\begin{array}{c}\text { Median } 15.68 \\
(8.48-29.36) \\
\end{array}$ & - & \\
\hline & $N=33$, Neonates of control group & - & - & $\begin{array}{c}\text { Median } 7.4 \\
(4.04-11.88) \\
\end{array}$ & - & \\
\hline & $N=48$, Group A, 60,000 IU D in 2nd trimester & $\begin{array}{c}\text { Median } 12.68 \\
(5.8-18.28) \\
\end{array}$ & - & $\begin{array}{c}\text { Median } 10.48 \\
(7.08-23.08) \\
\end{array}$ & - & \\
\hline & $N=31$, Neonates of group A & - & - & $\begin{array}{c}\text { Median } 11.28 \\
(6.04-17.2) \\
\end{array}$ & - & \\
\hline & $\begin{array}{l}N=48, \text { Group } \mathrm{B}, 120,000 \mathrm{IU} \mathrm{D}_{3} \text { in } 2 \mathrm{nd} \text { and } \\
\text { 3rd trimester }\end{array}$ & $\begin{array}{c}\text { Median } 12.8 \\
(5.8-18.28) \\
\end{array}$ & - & $\begin{array}{l}\text { Median } 23.48 \\
(15.36-35.76) \\
\end{array}$ & 38 & \\
\hline & $N=28$, Neonates of group B & - & - & $\begin{array}{l}\text { Median } 9.64 \\
(4.88-17.56)\end{array}$ & - & \\
\hline
\end{tabular}


Table 3. Cont

\begin{tabular}{|c|c|c|c|c|c|c|}
\hline \multirow{3}{*}{ Locale } & \multirow{3}{*}{ Study Subjects and Supplementation Protocols } & \multicolumn{4}{|c|}{ Vitamin D Status } & \multirow{3}{*}{ Reference } \\
\hline & & \multicolumn{2}{|c|}{ Before } & \multicolumn{2}{|c|}{ After } & \\
\hline & & $\begin{array}{c}25(\mathrm{OH}) \mathrm{D} \\
\text { Mean (SD) }\end{array}$ & $\%$ Deficient & $\begin{array}{c}\text { 25(OH)D } \\
\text { Mean (SD) }\end{array}$ & $\%$ Deficient & \\
\hline \multirow[t]{3}{*}{ Delhi $\left(28.3^{\circ} \mathrm{N}\right)$} & $\begin{array}{l}\text { Low birth weight term infants, } \\
\text { from all income groups. }\end{array}$ & - & - & - & - & \multirow[t]{3}{*}{$\begin{array}{c}\text { Kumar } \\
2011[126]\end{array}$} \\
\hline & $N=237$, Control group & - & - & $14.4(10.2)$ & 73.4 & \\
\hline & $\begin{array}{l}N=216, \text { Study group, started at } 7 \text { days after birth, } \\
1400 \mathrm{IU} \mathrm{D}_{3} \text { (dissolved in breast milk) per week, given } \\
\text { for } 6 \text { months }\end{array}$ & - & - & $22.0(9.0)$ & 43.5 & \\
\hline \multirow[t]{3}{*}{$\operatorname{Delhi}\left(28.3^{\circ} \mathrm{N}\right)$} & $\begin{array}{l}\text { Low birth weight term infants, from all } \\
\text { income groups. }\end{array}$ & - & - & - & - & \multirow[t]{3}{*}{$\begin{array}{c}\text { Trilok-Kuma1 } \\
2012[127]\end{array}$} \\
\hline & $N=187$, Control group & - & - & $15.1(10.5)$ & 72.19 & \\
\hline & $\begin{array}{l}N=164, \text { Study group, started at } 7 \text { days after birth, } \\
1400 \mathrm{IU} \mathrm{D}_{3} \text { (dissolved in breast milk) per week, given } \\
\text { for } 6 \text { months }\end{array}$ & - & - & $22.8(8.9)$ & 37.8 & \\
\hline \multirow[t]{5}{*}{ Delhi $\left(28.3^{\circ} \mathrm{N}\right)$} & Urban adolescent schoolgirls & - & 93.7 & - & - & \multirow{5}{*}{$\begin{array}{l}\text { Marwaha } \\
2010[128]\end{array}$} \\
\hline & $\begin{array}{l}N=60, \text { low income group, age } 12(2.8) \text { years, } \\
60,000 \mathrm{IU} \mathrm{D} \mathrm{D}_{3} / 2 \text { months, for } 1 \text { year }\end{array}$ & $12.48(0.67)$ & 98 & $21.2(1.22)$ & 38 & \\
\hline & $\begin{array}{l}N=64, \text { low income group, age } 11.4(3) \text { years, } \\
60,000 \mathrm{IU} \mathrm{D}_{3} / \text { month, for } 1 \text { year }\end{array}$ & $13.17(0.54)$ & 97 & $23.73(1.05)$ & 28 & \\
\hline & $\begin{array}{l}N=81 \text {, high income group, age } 11.6(2.7) \text { years, } 60,000 \\
\mathrm{IU} \mathrm{D}_{3} / 2 \text { months, for } 1 \text { year }\end{array}$ & $11.65(0.61)$ & 94 & $15.3(0.85)$ & 80 & \\
\hline & $\begin{array}{l}N=85 \text {, high income group, age } 11.7(2.8) \text { years, } 60,000 \\
\mathrm{IU} \mathrm{D}_{3} / \text { month, for } 1 \text { year }\end{array}$ & $12.32(0.55)$ & 88 & $19.97(0.80)$ & 57 & \\
\hline
\end{tabular}


Table 3. Cont.

\begin{tabular}{|c|c|c|c|c|c|c|}
\hline \multirow{3}{*}{ Locale } & \multirow{3}{*}{ Study Subjects and Supplementation Protocols } & \multicolumn{4}{|c|}{ Vitamin D Status } & \multirow{3}{*}{ Reference } \\
\hline & & \multicolumn{2}{|c|}{ Before } & \multicolumn{2}{|c|}{ After } & \\
\hline & & $\begin{array}{c}25(\mathrm{OH}) \mathrm{D} \\
\text { Mean (SD) }\end{array}$ & $\%$ Deficient & $\begin{array}{c}25(\mathrm{OH}) \mathrm{D} \\
\text { Mean (SD) }\end{array}$ & $\%$ Deficient & \\
\hline \multirow[t]{4}{*}{ Delhi $\left(28.3^{\circ} \mathrm{N}\right)$} & $\begin{array}{l}\text { Total } N=482 \text {, Adolescents, after } 60,000 \mathrm{IU}_{3} / \text { week, as } \\
\text { per each group. All subjects in all groups received } 600 \\
\text { IU } \mathrm{D}_{3} / \text { day for } 12 \text { weeks }\end{array}$ & - & - & - & - & $\begin{array}{c}{ }^{\ddagger} \text { Garg } \\
2013[129]\end{array}$ \\
\hline & Group A, 60,000IU $\mathrm{D}_{3} /$ week for 4 weeks & - & - & - & - & \\
\hline & Group B, $60,000 \mathrm{IU} \mathrm{D} /$ week for 6 weeks & - & - & $27.0(6.6)$ & - & \\
\hline & Group C, $60,000 \mathrm{IU} \mathrm{D}_{3} /$ week for 8 weeks & - & - & $28.0(8.7)$ & - & \\
\hline \multirow[t]{5}{*}{$\operatorname{Delhi}\left(28.3^{\circ} \mathrm{N}\right)$} & $\begin{array}{l}N=172, \text { Urban young women, nursing students, age } \\
21.7(4.4) \text { years }\end{array}$ & $9.3(3.37)$ & - & - & - & \multirow[t]{5}{*}{$\begin{array}{l}\text { Goswami } \\
2012[130]\end{array}$} \\
\hline & $N=43$, Group A, double placebo & $8.6(3.26)$ & - & $7.7(3.64)$ & - & \\
\hline & $N=43$, Group B, 1 gm calcium/day & $9.9(3.24)$ & - & $8.1(2.92)$ & - & \\
\hline & $\begin{array}{l}N=43, \text { Group } \mathrm{C}, 60,000 \mathrm{IU} \mathrm{D}_{3} / \text { week for } \\
8 \text { weeks, followed by } 60,000 \mathrm{IU} \mathrm{D}_{3} \text { twice/month for } \\
4 \text { months }\end{array}$ & $9.2(3.40)$ & - & $29.9(8.35)$ & - & \\
\hline & $\begin{array}{l}N=43 \text {, Group } \mathrm{D}, 1 \mathrm{gm} \text { calcium/day. Also } \\
60,000 \mathrm{IU} \mathrm{D} \mathrm{D}_{3} / \text { week for } 8 \text { weeks, followed by } \\
60,000 \mathrm{IU} \mathrm{D} \mathrm{D}_{3} \text { twice/month for } 4 \text { months }\end{array}$ & $9.5(3.47)$ & - & $27.0(9.54)$ & - & \\
\hline
\end{tabular}


Table 3. Cont

\begin{tabular}{|c|c|c|c|c|c|c|}
\hline \multirow{3}{*}{ Locale } & \multirow{3}{*}{ Study Subjects and Supplementation Protocols } & \multicolumn{4}{|c|}{ Vitamin D Status } & \multirow{3}{*}{ Reference } \\
\hline & & \multicolumn{2}{|c|}{ Before } & \multicolumn{2}{|c|}{ After } & \\
\hline & & $\begin{array}{c}25(\mathrm{OH}) \mathrm{D} \\
\text { Mean (SD) }\end{array}$ & $\%$ Deficient & $\begin{array}{c}25(\mathrm{OH}) \mathrm{D} \\
\text { Mean (SD) }\end{array}$ & $\%$ Deficient & \\
\hline \multirow[t]{3}{*}{ Delhi $\left(28.3^{\circ} \mathrm{N}\right)$} & $\begin{array}{l}\text { Urban adults, medical students, } \\
\text { age } 31.5(5) \text { years }\end{array}$ & - & 100 & - & - & \multirow[t]{3}{*}{$\begin{array}{c}\text { Gupta } \\
2010[131]\end{array}$} \\
\hline & $N=20$, Control group, $11 \mathrm{M}, 9 \mathrm{~F}$, double placebo & $8.44(3.76)$ & - & $11.88(6.0)$ & - & \\
\hline & $\begin{array}{l}N=20, \text { Study group, } 13 \mathrm{M}, 7 \mathrm{~F} \text {, received } \\
1 \mathrm{gm} \text { calcium/day for months and } 60,000 \mathrm{IU} \mathrm{D}_{3} / \text { week } \\
\text { for } 8 \text { weeks and then once per month for } 4 \text { months }\end{array}$ & $10.16(3.96)$ & - & $22.4(6.8)$ & - & \\
\hline \multirow[t]{2}{*}{$\operatorname{Delhi}\left(28.3^{\circ} \mathrm{N}\right)$} & $\begin{array}{l}N=23 \text {, Urban adults, age } \mathrm{F} 33.9(13.1) \text { years, } \\
\text { age M } 34 \text { (17) years. } 60,000 \mathrm{IU} \mathrm{D}_{3} / \text { week for } 8 \text { weeks. } \\
1 \text { gm calcium was given daily for } 8 \text { weeks. Subjects } \\
\text { measured at } 8 \text { weeks. }\end{array}$ & $5.4(1.2)$ & 100 & $32.96(8.29)$ & 4.3 & \multirow[t]{2}{*}{$\begin{array}{l}\text { Goswami } \\
2008[117]\end{array}$} \\
\hline & The subjects were measured again at 12 months. & & & $9.88(4.6)$ & 100 & \\
\hline \multirow[t]{4}{*}{ Delhi $\left(28.3^{\circ} \mathrm{N}\right)$} & $\begin{array}{l}\text { Urban postmenopausal women, age } 54.8 \text { (6.7) years. } \\
\text { All subjects in all groups received calcium } 1 \text { gm/day for } \\
3 \text { months. }\end{array}$ & - & $83.7 \%$ & - & - & \multirow[t]{4}{*}{$\begin{array}{l}\text { Agarwal } \\
2013[132]\end{array}$} \\
\hline & $N=21$, Control group A & $12.99(6.74)$ & - & $8.0(5.28)$ & 95.3 & \\
\hline & $N=25$, Group B, $500 \mathrm{IU} /$ day $\mathrm{D}_{3}$ for 3 months & $12.92(8.20)$ & - & $13.34(9.52)$ & 84.0 & \\
\hline & $N=18$, Group C, $1000 \mathrm{IU} /$ day $\mathrm{D}_{3}$ for 3 months & $14.38(11.07)$ & - & $23.71(11.71)$ & 33.33 & \\
\hline
\end{tabular}


Table 4. Vitamin D supplementation studies reporting improved bone health post-intervention, in ostensibly healthy Indians (adolescents and adults). All 25(OH)D values have been shown in $\mathrm{ng} / \mathrm{mL}$. To convert from $\mathrm{nM}$ to $\mathrm{ng} / \mathrm{mL}$, $\mathrm{nM}$ values were divided by (2.5). Vitamin $\mathrm{D}$ deficiency is defined as $25(\mathrm{OH}) \mathrm{D}<20 \mathrm{ng} / \mathrm{mL}$, insufficiency as $20-29 \mathrm{ng} / \mathrm{mL}$ and sufficiency as $\geq 30 \mathrm{ng} / \mathrm{mL}$. $\mathrm{D}_{3}$ is cholecalciferol and $\mathrm{D}_{2}$ is ergocalciferol. Calcium amount mentioned is of elemental calcium. Age of the subjects is in mean age (SD) years, unless otherwise indicated.

\begin{tabular}{|c|c|c|c|c|c|}
\hline \multirow{3}{*}{ Locale } & \multirow{3}{*}{ Study Subjects and Supplementation Protocols } & \multicolumn{3}{|r|}{ Vitamin D Status } & \multirow{3}{*}{ Reference } \\
\hline & & \multirow{2}{*}{$\begin{array}{c}\text { Before } \\
\text { 25(OH)D } \\
\text { Mean (SD) }\end{array}$} & \multicolumn{2}{|r|}{ After } & \\
\hline & & & $\begin{array}{l}25(\mathrm{OH}) \mathrm{D} \\
\text { Mean (SD) }\end{array}$ & Bone Health Status & \\
\hline \multirow{3}{*}{$\begin{array}{l}\text { Pune } \\
\left(18.5^{\circ} \mathrm{N}\right)\end{array}$} & $\begin{array}{l}\text { Urban, postmenarchal schoolgirls, age } 14-15 \text { years, } \\
\text { low income group. All the girls were shorter and } \\
\text { lighter compared to Indian norms. }\end{array}$ & - & - & - & \multirow{3}{*}{$\begin{array}{l}\text { Khadilkar } \\
2010[133]\end{array}$} \\
\hline & $\begin{array}{l}N=24, \text { Control group: placebo and } 250 \mathrm{mg} \\
\text { calcium/day for } 1 \text { year. }\end{array}$ & $\begin{array}{l}\text { Median } 8.32 \\
(5.08-12.16)\end{array}$ & $\begin{array}{c}\text { Median } 11.24 \\
(6.68-13.6)\end{array}$ & $\begin{array}{l}\text { Mean increase in } 25(\mathrm{OH}) \mathrm{D} \text { was } 19 \% \text {, mean decrease in } \\
\text { PTH was } 9 \% \text {. BMD showed no change. }\end{array}$ & \\
\hline & $\begin{array}{l}N=25 \text {, Study group: } 300,000 \mathrm{IU} \mathrm{D}_{2} \text { once every } \\
3 \text { months and } 250 \mathrm{mg} \text { calcium/day for } 1 \text { year. } \\
\text { Study group was divided into sub groups: (1) girls who } \\
\text { had menarche within } 2 \text { years and (2) girls who had } \\
\text { menarche for over } 2 \text { years, at the start of the study. }\end{array}$ & $\begin{array}{l}\text { Median } 9.8 \\
(5.08-13.28)\end{array}$ & $\begin{array}{l}\text { Median } 30.08 \\
(25.68-34.2)\end{array}$ & $\begin{array}{l}\text { Overall, } 25(\mathrm{OH}) \mathrm{D} \text { increased by } 68 \% \text { and PTH decreased } \\
\text { by } 27 \% \text {. No significant changes were observed in } \\
\text { subgroup ( } 2 \text { ). However, in subgroup (1) total bone } \\
\text { mineral content (TB BMC) and total bone area (TB BA) } \\
\text { increased and lumbar spine BMC was higher. }\end{array}$ & \\
\hline \multirow{4}{*}{$\begin{array}{l}\text { Pune } \\
\left(18.5^{\circ} \mathrm{N}\right)\end{array}$} & $\begin{array}{l}\text { Urban, premenarchal schoolgirls, age } 9.8 \text { (1) years. All } \\
\text { the girls were shorter and lighter compared to Indian } \\
\text { norms. All subjects received } 300,000 \mathrm{IU} \mathrm{D}_{3} \text { once every } \\
3 \text { months, for } 1 \text { year. }\end{array}$ & $\begin{array}{l}65.7 \% \\
\text { vitamin D } \\
\text { deficient }\end{array}$ & - & $\begin{array}{l}\text { TB BMC, TB BA, TB BMD, TB LBM (lean body mass) } \\
\text { and TB fat } \% \text { increased significantly in all three groups } \\
\text { over baseline. There was no significant difference } \\
\text { between the results of study groups }(\mathrm{Ca}) \text { and }(\mathrm{Ca}+\mathrm{MZ}) \text {. }\end{array}$ & \multirow{4}{*}{$\begin{array}{l}\text { Khadilkar } \\
2012[134]\end{array}$} \\
\hline & $N=69$, Control group, two placebos. & $23.08(10.68)$ & - & Total body BMC increased by $17.6 \%$ & \\
\hline & $\begin{array}{l}N=70, \text { Study group }(\mathrm{Ca}), 500 \mathrm{mg} \text { calcium } \\
6 \text { days/week, for } 1 \text { year. }\end{array}$ & $24.76(10.36)$ & - & Total body BMC increased by $22.3 \%$. & \\
\hline & $\begin{array}{l}N=71, \text { Study group }(\mathrm{Ca}+\mathrm{MZ}), 500 \mathrm{mg} \text { calcium and } \\
\text { multivitamin }+ \text { zinc }\left(\text { Becosule- } Z^{\circledR}\right) 1 \text { tablet } \\
6 \text { days/week, for } 1 \text { year. }\end{array}$ & $26.36(10.92)$ & - & Total body BMC increased by $20.8 \%$. & \\
\hline
\end{tabular}


Table 5. Vitamin D food fortification studies in ostensibly healthy Indians. All 25(OH)D values have been shown in $\mathrm{ng} / \mathrm{mL}$. To convert from $\mathrm{nM}$ to $\mathrm{ng} / \mathrm{mL}, \mathrm{nM}$ values were divided by (2.5). Vitamin D deficiency is defined as $25(\mathrm{OH}) \mathrm{D}<20 \mathrm{ng} / \mathrm{mL}$, insufficiency as $20-29 \mathrm{ng} / \mathrm{mL}$ and sufficiency as $\geq 30 \mathrm{ng} / \mathrm{mL}$. Age of the subjects is in mean age (SD) years.

\begin{tabular}{|c|c|c|c|c|c|c|c|c|}
\hline \multirow{3}{*}{ Locale } & \multirow{3}{*}{ Study Subjects and Fortification Protocols } & \multicolumn{6}{|c|}{ Vitamin D Status } & \multirow{3}{*}{ Reference } \\
\hline & & \multicolumn{3}{|c|}{ Before } & \multicolumn{3}{|c|}{ After } & \\
\hline & & $\begin{array}{c}25(\mathrm{OH}) \mathrm{D} \\
\text { Mean (SD) }\end{array}$ & $\%$ Deficient & $\%$ Sufficient & $\begin{array}{c}25(\mathrm{OH}) \mathrm{D} \\
\text { Mean (SD) }\end{array}$ & $\%$ Deficient & $\%$ Sufficient & \\
\hline \multirow{4}{*}{$\begin{array}{l}\text { Delhi } \\
\left(28.3^{\circ} \mathrm{N}\right) \\
\text { Northern } \\
\text { India }\end{array}$} & $\begin{array}{l}\text { Total } N=713 \text {, Urban school children and } \\
\text { adolescents, age } 11.74(1.05) \text { years, } 300 \mathrm{M}, 413 \mathrm{~F} \text {. } \\
\text { All were given unfortified milk for } 12 \text { weeks and } \\
\text { then divided into } 3 \text { groups. }\end{array}$ & $11.69(5.36)$ & 92.3 & 0.7 & $20.44(9.88)$ & - & - & \multirow{4}{*}{$\begin{array}{l}\text { Khadgawa } \\
2013[123]\end{array}$} \\
\hline & $\begin{array}{l}N=237, \text { Control group: Unfortified milk } \\
200 \mathrm{~mL} / \text { day for } 12 \text { weeks, } 102 \mathrm{M}, 135 \mathrm{~F}\end{array}$ & $11.74(5.23)$ & 93.6 & - & $10.83(5.24)$ & 94.0 & & \\
\hline & $\begin{array}{l}N=243, \text { Study Group A, fortified milk, } 600 \mathrm{IU} \\
\mathrm{D}_{3} / 200 \mathrm{~mL} / \text { day for } 12 \text { weeks, } 97 \mathrm{M}, 146 \mathrm{~F}\end{array}$ & $11.42(5.24)$ & 95.0 & 1.23 & $22.87(6.75)$ & 30.0 & 12.34 & \\
\hline & $\begin{array}{l}N=233, \text { Study Group B, fortified milk, } 1000 \mathrm{IU} \\
\mathrm{D}_{3} / 200 \mathrm{~mL} / \text { day for } 12 \text { weeks, } 101 \mathrm{M}, 132 \mathrm{~F}\end{array}$ & $11.94(5.62)$ & 87.9 & 0.42 & $27.67(8.47)$ & 18.9 & 36.05 & \\
\hline \multirow{3}{*}{$\begin{array}{l}\text { Pune } \\
\left(18.5^{\circ} \mathrm{N}\right) \\
\text { Western } \\
\text { India }\end{array}$} & \multicolumn{7}{|c|}{$\begin{array}{l}\text { Total } N=58 \text {, Urban children, low income group, age } 2.7(0.52) \text { years. While both groups received } \mathrm{D}_{3} \text { fortified laddoos. Control group received } \\
\text { only } 156 \mathrm{mg} \text { of calcium, as opposed to } 405 \mathrm{mg} \text { of calcium to the study group. }\end{array}$} & \multirow{3}{*}{$\begin{array}{c}\text { Ekbote } \\
2011[122]\end{array}$} \\
\hline & $\begin{array}{l}N=28, \text { Control Group, } 1 \text { fortified laddoo } *, 156 \mathrm{mg} \\
\text { of calcium, } 5 \text { times/week for a year. Also given, } 1 \\
\text { laddoo with } 30,000 \mathrm{IU} \mathrm{D}_{3} / \text { month for } 1 \text { year. }\end{array}$ & $7.56(10.8)$ & 84 & - & $23.24(4.76)$ & - & - & \\
\hline & $\begin{array}{l}N=30, \text { Study Group, } 1 \text { fortified laddoo, } 405 \mathrm{mg} \text { of } \\
\text { calcium, } 5 \text { times/week for a year. Also given, } \\
1 \text { laddoo with } 30,000 \mathrm{IU} \mathrm{D}_{3} / \text { month for } 1 \text { year. }\end{array}$ & $10.0(10.84)$ & 83 & - & $25.75(9.56)$ & - & - & \\
\hline
\end{tabular}

* A laddoo is an Indian cereal-legume snack, spherical, about $4 \mathrm{~cm}$ in diameter and weight $50 \mathrm{~g}$. The ingredients for unfortified laddoos, were ragi (Eleusine coracana) and whole dried Bengal gram (Cicer arietinum) $7.5 \mathrm{~g}$ each, sesame seeds (Sesamum indicum) and poppy seeds (Papaner somniferum) $5 \mathrm{~g}$ each, $5 \mathrm{~g}$ of clarified butter (Ghee) and $15 \mathrm{gm}$ of refined palm sugar. 


\section{Food Items Which Could Be Fortified with Vitamin D in India}

1. Milk: The whole array of different grades of milk available could be fortified-whole milk, toned, double toned and skim milk.

2. Milk curd and yogurt.

3. Infant formulas.

4. Butter, ghee (clarified butter) and oils, to use as spreads or to spike already cooked food.

5. Soy milk, soy curd (tofu), orange juice and mango juice may be fortified to cater to the needs of the lactose intolerant individuals and those who are allergic to milk proteins. Processed cheese also has very low lactose content and is rich in calcium and may be fortified for the benefit of the lactose intolerant. Due to high prevalence of dyslipidemia, metabolic syndrome and cardiovascular diseases in India, these fortified items will also offer healthier choices to the general population.

6. Widely consumed and affordable staple food items such as chapati flour, maida (all purpose wheat flour, used to make bread and other bakery products), rice and rice flour may be suitable vehicles for fortification strategies in the Indian scenario.

\section{Foods Fortified with Vitamin D Available in the Indian Market}

Vitamin D fortified milk from Amul ${ }^{\circledR}$ (an Indian dairy cooperative, located in Anand, Gujarat, India) is the only fortified milk product found in the general market. It is $4.5 \%$ fat, homogenized milk fortified with calcium $150 \mathrm{mg}$, vitamin A $75 \mu \mathrm{g}$ and vitamin D $0.5 \mu \mathrm{g}$ (20 IU), etc., per $100 \mathrm{~mL}$. The expiry date of this milk is 120 days if the carton is unopened. Incidentally, with a $10 \%$ or more loss per month at $4{ }^{\circ} \mathrm{C}$, there is not much vitamin D left by 120 days. It may be hoped that storage temperatures are always adhered to. But in India this is a remote possibility due to economical and technical limitations. In a brief survey, most retailers reported that the Amul ${ }^{\circledR}$ milk cartons supplied to them were generally one month past expiry date already at the time of delivery and that the demand for this product was very low. Cost per liter is INR 48 (as on 12 January 2013) as opposed to the cost of unfortified milk (INR 30).

Kellogg's breakfast cereals fortified with vitamin D along with other micronutrients are also available. However, the exorbitant prices of these products are essentially prohibitive for consumption by the common people of India.

\section{Estimated Burden of Bone Diseases on Indian Healthcare System}

There is no "national body" instituted by the government of India, to study and document the prevalence of bone diseases in India. The following figures pertaining bone health were perforce taken from research articles. In India, bone diseases such as rickets, osteomalacia and osteoporosis have been [67,135-137] and still are widely prevalent and formidable problems of our nation. As per 2001 Census Report about 163 million people were above the age of 50 years. This figure will be much bigger from the 2011 Census Report and may exceed 200 million. About 15\%-20\% of persons above the age of 50 years would be developing osteoporosis [136]. As presented in this review, BMD studies of ostensibly healthy Indians show that a significant proportion of younger Indians too are suffering 
from this silent disease. As the early signs of osteoporosis are diagnosed with accuracy, BMD data will add to these already astounding figures. Some staggering figures and estimates pertaining rickets, osteomalacia and osteoporosis are mentioned in some reviews [136,137].

Vitamin D status in India is grim not only in the lower and but also in the upper socioeconomic classes. For the sake of simplicity and argument, let us consider only the skeletal benefits of vitamin D. Vitamin D sufficiency in women of reproductive age would at the very least result in -improved women's health, improved outcome of childbirth and birth of infants who may have a better chance of a healthy existence from the beginning of their lives. Vitamin D sufficiency in growing children would mean allowing for their full growth potential-physically, mentally and psychologically. In children, rickets translates into life-long deformity, osteomalacia - a painful and subpar existence. Osteoporosis is a silent disease tethered to a constant threat of fractures to the unbeknownst afflicted. In elderly patients, especially hip fractures result in the end of an independent existence. Notably, most people in India do not have health insurance. Hospitalization of patients with hip fractures is much longer than for those being treated for cancers. For those who cannot afford hospitalization for treatment, it is a long, agonizing and often an unending wait for resurrection. This fact indicates the heavy load on the healthcare system and the economy of the nation due to bone diseases alone.

\section{Government's Intervention Required}

Vitamin D sufficiency status may not be treated as a "feel good status" for the affluent who can afford medical expenses and expensive vitamin D supplements. Vitamin D is prevalent across all socioeconomic strata. It is imperative that policymakers understand the gravity of the situation pertaining vitamin D status and as a consequence - the untold burden on the healthcare system in India. The information presented in this article ought to persuade policymakers to take substantive measures towards attaining vitamin D sufficiency. Actions needed to be taken by the government of India are as follows:

1 Revision of RDA (Recommended Daily Allowance) values for vitamin D and calcium intake, by ICMR (Indian Council of Medical Research) is imperative.

2 Educational Programs: Vitamin D deficiency is the world's most under-diagnosed and under-treated disease. There is great need for awareness of its implications among physicians and the general public at large. Adequate investment of money, time and effort is required to develop, launch and sustain public awareness programs.

2.1 The curricula of medical colleges need to be updated pertaining vitamin $\mathrm{D}$ status of the Indian populace. Inclusion of pertinent and updated information pertaining vitamin $\mathrm{D}$, and its skeletal and extraskeletal benefits is required.

2.2 Making bone and mineral health a priority: All healthcare facilities, including all primary health care facilities should institute awareness programs to educate the physicians and the local residents about the need for vitamin D sufficiency.

2.3 Active participation of social organizations is required. Social workers and school teachers need to be duly informed and educated, so they can spread the word about necessity for vitamin D sufficiency and the ways to achieve it. 
2.4 Aggressive government sponsored mass media programs, with the aid of tele-media and print media are required to educate the masses about the grim vitamin D deficiency status in India. The masses should be educated on the benefits of a combination of sun exposure, vitamin D fortified food items, supplements and regular physical exercise.

2.5 A need for sufficient calcium intake along with vitamin D must be stressed at all times.

3 Vitamin D supplements: Affordable, good quality and readily available vitamin D supplements for the masses are needed. Vitamin D supplements should be made available at all primary care health centers to pregnant women and lactating women.

4 Fortification of foods with vitamin D: First and foremost possibility thinking is required. Indian government has successfully launched food-fortification programs before. The most visible result to the public eye being-iodized salt. Fortification of food with vitamin D is doable. Political and administration's will and support should be available from the development stage of the fortification program and equally importantly sustained.

4.1 Involvement of the food industry by encouraging private enterprises operating at the national and local level is required. Support in terms of technical expertise pertaining production of fortified food items, availability of standardized vitamin D formulation(s) and information on the marketing potential of the fortified items should be made available.

4.2 Effective legislation to ensure good quality and regulated vitamin D fortified foods at minimal cost to the end consumer is required. That said, both the administration and legislature should very importantly be facilitative and not be restrictive or punitive to those who are striving towards attaining better bone and mineral health of the masses.

5 School going children could benefit from the following:

5.1 Educators should emphatically teach the need for vitamin D sufficiency and benefits of a healthy lifestyle. Inclusion of the benefits of vitamin D in the ken of the kids may perchance spread this information to their (unaware) kin too.

5.2 Mandatory distribution of vitamin D fortified foods at midday meals in schools.

5.3 Daily physical exercise should be made compulsory in schools.

6 Affordable and widely accessible testing facilities for vitamin D levels should be made available to individuals who are at high risk of clinical vitamin D deficiency.

7 Reliable and sensitive technology such as DEXA should be made available at minimal cost for screening bone mineral density in individuals at high risk, with easy accessibility, throughout India.

8 Last, but not the least, government should extend support to research groups, so that the impact of supplementation programs and fortification strategies in actual practice may be studied and monitored and more efficacious ways developed. Continued research and epidemiological studies are required, to clearly state the enormity of the vitamin D deficiency status and its implications on general health of Indians, countrywide. Vitamin D status from western, eastern, northeastern India and the Himalayan regions and are still either few or lacking. Also, the very poor and the marginalized citizens have not been included in such studies. 


\section{A Lagniappe for the Readers: Other Countries of the Indian Subcontinent Present a Similar Scenario Pertaining Vitamin D Status}

Other countries of the Indian subcontinent: Pakistan, Bangladesh, Nepal, Sri Lanka, Myanmar and Bhutan share the same geographic locale and socioeconomic culture with India. Data were compiled from these countries too. Vitamin D deficiency is highly prevalent in these countries (Table 6). One report was available from Pakistan pertaining bone health of ostensibly healthy subjects. In a cohort of 140 rural postmenopausal women from Khazana $\left(34.7^{\circ} \mathrm{N}\right)$ and Nahaqi $\left(34.2^{\circ} \mathrm{N}\right)$, age $52(\mathrm{SD} 2)$ years, $42 \%$ had osteopenia and $28 \%$ had osteoporosis. 25(OH)D levels correlated with BMD [138]. No reports were available from other countries of the Indian subcontinent pertaining vitamin D status and its correlation with BMD. One supplementation study from Bangladesh showed significant improvement in the vitamin D status (Table 7). One supplementation study from Pakistan showed significant improvement in the vitamin D status and improved bone health (Table 8). No food fortification studies were available from any of these countries. From the available data, it is clear that vitamin D scenario in these countries is similar to that in India. The data from other countries of the Indian subcontinent also show that though India may be economically more advanced that some of its neighbors, the vitamin D scenario is similar all over the subcontinent.

\section{Conclusions}

Widespread prevalence of vitamin D deficiency in India is undeniable. Factually, sun exposure is an untenable solution, for most individuals in India, towards attaining vitamin D sufficiency. Low calcium intake in conjunction with vitamin $\mathrm{D}$ deficiency makes matters worse. The need for improvement in vitamin status of the Indian population is both important and urgent. The Indian government needs to take substantive measures in this direction. Revision of RDA for calcium and vitamin D is required. Better facilities and technologies should be made available countrywide to enable timely diagnosis of clinical manifestations of vitamin D deficiency in individuals who need attention by the clinicians. Population-based programs at the national level must be developed to increase awareness of the problem at hand, to provide affordable vitamin D supplements and also to provide vitamin D fortified foods to the Indian populace at large. Research in this field needs continued support to provide a comprehensive picture of the ongoing vitamin D problem and also to study and monitor the effect(s) of a partnership between the government, healthcare system, industry and consumers, aimed at improving the vitamin D status in India. 
Table 6. Vitamin D status of ostensibly healthy subjects from other countries of the Indian subcontinent. All 25(OH)D values have been shown in $\mathrm{ng} / \mathrm{mL}$. To convert from $\mathrm{nM}$ to $\mathrm{ng} / \mathrm{mL}, \mathrm{nM}$ values were divided by (2.5). Vitamin $\mathrm{D}$ deficiency is defined as $25(\mathrm{OH}) \mathrm{D}<20 \mathrm{ng} / \mathrm{mL}$, insufficiency as 20-29 ng/mL and sufficiency as $\geq 30 \mathrm{ng} / \mathrm{mL}$. Age of the subjects is in mean age (SD) years, unless otherwise indicated.

\begin{tabular}{|c|c|c|c|c|c|c|c|}
\hline \multirow[b]{2}{*}{ Locale } & \multirow{2}{*}{\multicolumn{2}{|c|}{ Study Subjects }} & \multirow{2}{*}{$\begin{array}{l}25(\mathrm{OH}) \mathrm{D}(\mathrm{ng} / \mathrm{mL}) \\
\quad \text { Mean }(\mathrm{SD})\end{array}$} & \multicolumn{3}{|c|}{ Vitamin D Status } & \multirow[b]{2}{*}{ Reference } \\
\hline & & & & $\begin{array}{c}\% \\
\text { Deficient }\end{array}$ & $\begin{array}{c}\% \\
\text { Insufficient }\end{array}$ & $\begin{array}{c}\% \\
\text { Sufficient }\end{array}$ & \\
\hline \multicolumn{8}{|l|}{ PAKISTAN } \\
\hline \multirow{3}{*}{$\begin{array}{l}\text { Lahore }\left(31.5^{\circ} \mathrm{N}\right) \\
\text { \& Rawalpindi } \\
\left(33.6^{\circ} \mathrm{N}\right)\end{array}$} & $N=92$ & $\begin{array}{l}\text { Adults, median age } 29(11-75) \text { years, } \\
\text { rural \& urban. }\end{array}$ & $\begin{array}{c}\text { Median } 29.7 \\
(3.0-63.1) \\
\end{array}$ & - & - & - & \multirow[t]{3}{*}{$\begin{array}{c}\text { Rashid } \\
1983[139]\end{array}$} \\
\hline & $N=48$ & $\mathrm{M}$ & $33.0(11.0)$ & - & - & - & \\
\hline & $N=44$ & $\mathrm{~F}$ & $27.0(11.3)$ & - & - & - & \\
\hline \multirow{3}{*}{$\begin{array}{l}\text { Karachi } \\
\left(24.8^{\circ} \mathrm{N}\right)\end{array}$} & Total $N=123$ & Urban adults, age 32.7 (8.7) years, hospital staff & $16.44(3.84)$ & 69.9 & 21.1 & 8.9 & \multirow{3}{*}{$\begin{array}{l}\text { Mansoor } \\
2010[140\end{array}$} \\
\hline & $N=53$ & $\mathrm{~F}$ & $14.88(9.2)$ & - & - & - & \\
\hline & $N=70$ & $\mathrm{M}$ & $17.64(3.88)$ & - & - & - & \\
\hline $\begin{array}{l}\text { Karachi } \\
\left(24.8^{\circ} \mathrm{N}\right)\end{array}$ & $N=305$ & $\begin{array}{l}\text { Urban adults, } F \text {, low, middle and high income } \\
\text { groups equally represented, } \\
\text { age } 31.97(8.00) \text { years }\end{array}$ & $8.70(8.64)$ & 90.5 & 5.2 & 4.3 & $\begin{array}{c}\text { Khan } \\
2012[141]\end{array}$ \\
\hline \multirow[t]{2}{*}{$\begin{array}{l}\text { Karachi } \\
\left(24.8^{\circ} \mathrm{N}\right)\end{array}$} & $N=50$ & $\begin{array}{l}\text { Pregnant women, age } 28.16(4.4) \text { years, low and } \\
\text { middle income group }\end{array}$ & $24.1(11.70)$ & 46 & 32 & 22 & \multirow[t]{2}{*}{$\begin{array}{c}\text { Karim } \\
2011[142\end{array}$} \\
\hline & $N=50$ & Cord blood/neonates & $20.4(10.99)$ & - & - & - & \\
\hline \multirow[t]{2}{*}{$\begin{array}{l}\text { Karachi } \\
\left(24.8^{\circ} \mathrm{N}\right)\end{array}$} & $N=75$ & $\begin{array}{l}\text { Pregnant women at term, age } 26(6.5) \text { years, low } \\
\text { income group }\end{array}$ & $\begin{array}{c}\text { Preterm } 16.89(7.83) \\
\text { Term } 13.19(6.74) \\
\end{array}$ & 72 & 17 & 11 & \multirow[t]{2}{*}{$\begin{array}{c}\text { Hossain } \\
2011[143]\end{array}$} \\
\hline & $N=75$ & Cord blood/neonates & $\begin{array}{c}\text { Preterm } 21.91(9.73) \\
\text { Term } 15.81(9.56) \\
\end{array}$ & 72 & 17 & 11 & \\
\hline \multirow{6}{*}{$\begin{array}{l}\text { Karachi } \\
\left(24.8^{\circ} \mathrm{N}\right)\end{array}$} & $N=62$ & Exclusively breastfed Infants & $13.83(10.62)$ & - & - & - & \multirow{6}{*}{$\begin{array}{c}\text { Atiq } \\
1998[144]\end{array}$} \\
\hline & $N=62$ & Mothers & $12.8(8.98)$ & - & - & - & \\
\hline & $N=37$ & Breastfed infants, age 6 weeks -11 months & $8.98(6.56)$ & - & - & - & \\
\hline & High income & Mothers, housewives, mostly indoors & $10.6(9.64)$ & - & - & - & \\
\hline & $N=25$ & Breastfed infants, age 6 weeks -11 months & $20.93(15.7)$ & - & - & - & \\
\hline & Low income & Mothers, working & $15.90(6.03)$ & - & - & - & \\
\hline
\end{tabular}


Table 6. Cont

\begin{tabular}{|c|c|c|c|c|c|c|c|}
\hline \multirow[b]{2}{*}{ Locale } & \multirow{2}{*}{\multicolumn{2}{|c|}{ Study Subjects }} & \multirow{2}{*}{$\begin{array}{c}25(\mathrm{OH}) \mathrm{D}(\mathrm{ng} / \mathrm{mL}) \\
\text { Mean }(\mathrm{SD})\end{array}$} & \multicolumn{3}{|c|}{ Vitamin D Status } & \multirow[b]{2}{*}{ Reference } \\
\hline & & & & $\begin{array}{c}\% \\
\text { Deficient }\end{array}$ & $\begin{array}{c}\% \\
\text { Insufficient }\end{array}$ & $\begin{array}{c}\% \\
\text { Sufficient }\end{array}$ & \\
\hline \multicolumn{8}{|l|}{ BANGLADESH } \\
\hline \multirow[t]{2}{*}{$\begin{array}{l}\text { Dhaka } \\
\left(23.7^{\circ} \mathrm{N}\right)\end{array}$} & $N=99$ & $\begin{array}{l}\text { Adults, } F \text {, low income level, age } 16-40 \text { years, } \\
88 \% \text { housewives }\end{array}$ & $\begin{array}{l}\text { Median 14.68 } \\
\text { (range 10-48) }\end{array}$ & - & - & - & \multirow[t]{2}{*}{$\begin{array}{c}\text { Islam } \\
2002[145]\end{array}$} \\
\hline & $N=90$ & $\begin{array}{l}\text { Adults, F, high income level, age } 16-40 \text { years, } \\
76 \% \text { housewives }\end{array}$ & $\begin{array}{l}\text { Median 17.4 } \\
\text { (range 10-48) }\end{array}$ & - & - & - & \\
\hline \multirow[t]{2}{*}{$\begin{array}{l}\text { Dhaka } \\
\left(23.7^{\circ} \mathrm{N}\right)\end{array}$} & $N=36$ & $\begin{array}{l}\text { Adults, F, high income level, age } 22.3 \text { (1.9) years, } \\
\text { unveiled }\end{array}$ & $12.12(9.04)$ & - & - & - & \multirow[t]{2}{*}{$\begin{array}{c}\text { Islam } \\
2006[146]\end{array}$} \\
\hline & $N=30$ & $\begin{array}{l}\text { Adults, F, medium income level, age } 47.7 \text { ( 9.4) } \\
\text { years, veiled/purdah }\end{array}$ & $12.4(4.4)$ & - & - & - & \\
\hline $\begin{array}{l}\text { Dhaka } \\
\left(23.7^{\circ} \mathrm{N}\right)\end{array}$ & $N=200$ & $\begin{array}{l}\text { Adults, F, urban factory workers, low income } \\
\text { group, age } 22.6 \text { (3.7) years }\end{array}$ & $14.68(4.48)$ & 88.5 & - & - & $\begin{array}{c}\text { Islam } \\
2008[147]\end{array}$ \\
\hline $\begin{array}{l}\text { Sylhet } \\
\left(24.9^{\circ} \mathrm{N}\right)\end{array}$ & $N=29$ & $\begin{array}{l}\text { Infants, age } 71 \text { (32) days, } 25 \mathrm{M}, 4 \mathrm{~F} \text {, rural, low } \\
\text { income group }\end{array}$ & $14.68(6.84)$ & - & - & - & $\begin{array}{c}\text { Roth } \\
2010[148]\end{array}$ \\
\hline $\begin{array}{l}\text { Matlab } \\
\left(23.3^{\circ} \mathrm{N}\right) \\
\end{array}$ & $N=98$ & $\begin{array}{l}\text { Cord blood, neonates of rural women/mothers, } \\
\text { age } 25.8 \text { (5.9) years }\end{array}$ & $\begin{array}{c}\text { Median } \\
23 \cdot 8(18 \cdot 6-30 \cdot 8) \\
\end{array}$ & - & - & - & $\begin{array}{c}\text { Doi } \\
2011[149] \\
\end{array}$ \\
\hline Dhaka $\left(23.7^{\circ} \mathrm{N}\right)$ & $N=76$ & $\begin{array}{l}\text { Pregnant women, } 20 \text { weeks of gestation, } \\
\text { age } 21.55 \text { (4) years }\end{array}$ & $24.86(1.02)$ & - & - & 34.21 & $\begin{array}{c}\text { Ullah } \\
2013[150]\end{array}$ \\
\hline \multicolumn{8}{|l|}{ NEPAL } \\
\hline $\begin{array}{l}\text { Sarlahi } \\
\left(26.5^{\circ} \mathrm{N}\right)\end{array}$ & $N=1163$ & $\begin{array}{l}\text { Rural F, pregnant, age } 23.6 \pm 6.0 \text { years, } \\
\text { gestational age } 10.9(4.6) \text { week. }\end{array}$ & $20.44(9.85)$ & - & - & - & $\begin{array}{c}\text { Jiang } \\
2005[151] \\
\end{array}$ \\
\hline \multicolumn{8}{|l|}{ SRI LANKA } \\
\hline \multirow{2}{*}{$\begin{array}{l}\text { Kandy } \\
\left(7.2^{\circ} \mathrm{N}\right)\end{array}$} & $N=85$ & Adults, $\mathrm{M}$, age $47.0(8.3)$ years. & $25.2(9.12)$ & $34 \cdot 1$ & - & - & \multirow{2}{*}{$\begin{array}{c}\text { Meyer } \\
2008[152]\end{array}$} \\
\hline & $N=111$ & Adults, F, age $46.4(7.8)$ years. & $18.96(6.32)$ & $58 \cdot 6$ & - & - & \\
\hline \multirow{2}{*}{ Galle $\left(6.2^{\circ} \mathrm{N}\right)$} & $N=122$ & Preschool children, M, age 45.93 (9.8) months & $34.8(13.4)$ & - & - & - & \multirow{2}{*}{$\begin{array}{r}\text { Hettiarachch } \\
2012[153]\end{array}$} \\
\hline & $N=126$ & Preschool children, F, age 46.56 (8.5) months & $32.62(14.8)$ & - & - & - & \\
\hline
\end{tabular}


Table 7. Vitamin D supplementation studies in ostensibly healthy subjects from other countries of the Indian subcontinent. All $25(\mathrm{OH}) \mathrm{D}$ values have been shown in $\mathrm{ng} / \mathrm{mL}$. To convert from $\mathrm{nM}$ to $\mathrm{ng} / \mathrm{mL}, \mathrm{nM}$ values were divided by (2.5). Vitamin D deficiency is defined as $25(\mathrm{OH}) \mathrm{D}<20 \mathrm{ng} / \mathrm{mL}$, insufficiency as $20-29 \mathrm{ng} / \mathrm{mL}$ and sufficiency as $\geq 30 \mathrm{ng} / \mathrm{mL}$. D3 is cholecalciferol.

\begin{tabular}{|c|c|c|c|c|c|c|}
\hline \multirow{3}{*}{ Locale } & \multirow{3}{*}{ Study Subjects and Supplementation Protocols } & \multicolumn{4}{|c|}{ Vitamin D Status } & \multirow{3}{*}{ Reference } \\
\hline & & \multicolumn{2}{|c|}{ Before } & \multicolumn{2}{|c|}{ After } & \\
\hline & & $\begin{array}{c}25(\mathrm{OH}) \mathrm{D} \\
\text { Mean (SD) }\end{array}$ & $\%$ Deficient & $\begin{array}{c}25(\mathrm{OH}) \mathrm{D} \\
\text { Mean (SD) }\end{array}$ & $\%$ Deficient & \\
\hline \multicolumn{7}{|c|}{ PAKISTAN One report is included in Table 8} \\
\hline \multicolumn{7}{|c|}{ BANGLADESH } \\
\hline \multirow{5}{*}{$\begin{array}{c}\text { Dhaka } \\
\left(23.7^{\circ} \mathrm{N}\right)\end{array}$} & Pregnant women, age 22.4 (SD 3.5) years, 26-29 weeks of gestation, & - & - & - & - & \multirow{5}{*}{$\begin{array}{c}\text { Roth } \\
2013 \text { [154] }\end{array}$} \\
\hline & $N=80$, Control group, placebo & $17.6(8.36)$ & 66.25 & $15.36(7.24)$ & 79.3 & \\
\hline & $N=67$, Cord blood/neonates of control group & - & - & $15.6(7.48)$ & 80.5 & \\
\hline & $N=80$, Study group, received 35,000 IU D3/week until delivery & $18.16(7.36)$ & 62.5 & $53.76(12.28)$ & 0 & \\
\hline & $N=65$, Cord blood/neonates of study group & - & - & $41.12(11.44)$ & 4.6 & \\
\hline
\end{tabular}

Table 8. Vitamin D supplementation studies reporting improved bone health post-intervention, in ostensibly healthy subjects from other countries of the Indian subcontinent: All 25(OH)D values have been shown in $\mathrm{ng} / \mathrm{mL}$. To convert from $\mathrm{nM}$ to $\mathrm{ng} / \mathrm{mL}, \mathrm{nM}$ values were divided by (2.5). Vitamin D deficiency is defined as $25(\mathrm{OH}) \mathrm{D}<20 \mathrm{ng} / \mathrm{mL}$, insufficiency as $20-29 \mathrm{ng} / \mathrm{mL}$ and sufficiency as $\geq 30 \mathrm{ng} / \mathrm{mL}$. D3 is cholecalciferol. Calcium amount mentioned is that of elemental calcium.

\begin{tabular}{|c|c|c|c|c|c|}
\hline \multirow{3}{*}{ Locale } & \multirow{3}{*}{ Study Subjects and Supplementation Protocols } & \multicolumn{3}{|c|}{ Vitamin D Status } & \multirow{3}{*}{ Reference } \\
\hline & & \multirow{2}{*}{$\begin{array}{c}\text { Before } \\
25(\mathrm{OH}) \mathrm{D} \\
\text { Mean }(\mathrm{SD})\end{array}$} & \multicolumn{2}{|c|}{ After } & \\
\hline & & & $\begin{array}{c}25(\mathrm{OH}) \mathrm{D} \\
\text { Mean (SD) }\end{array}$ & Bone Health Status & \\
\hline \multicolumn{6}{|c|}{ PAKISTAN } \\
\hline $\begin{array}{l}\text { Lahore } \\
\left(31.5^{\circ} \mathrm{N}\right)\end{array}$ & $\begin{array}{l}N=53 \text {, premenopausal women, age } 41.3 \text { (SD } 8.2 \text { ) } \\
\text { years. All subjects had anterior tibial tenderness (ATT). } \\
\text { Subjects received a total of } 1,800,000 \text { IU intramuscular } \\
\text { D3, in } 3 \text { doses of } 600,000 \mathrm{IU} \text { each, on alternate days. } \\
\text { All subjects received } 1.2 \mathrm{gm} \text { calcium/day for } 3 \text { months. }\end{array}$ & $\begin{array}{c}12.1(17.5) \\
\text { 81.1\% were vitamin D } \\
\text { deficient }\end{array}$ & 51.9 (no SD) & $\begin{array}{l}\text { Significant improvement in ATT was observed. } \\
88.7 \% \text { women attained vitamin D sufficiency } \\
\text { and } 92.4 \% \text { had normalization of PTH levels. } \\
\text { Change in ATT correlated with change in PTH, } \\
\text { but did not correlate with 25(OH)D levels. }\end{array}$ & $\begin{array}{c}\text { Ali } \\
2013 \text { [155] }\end{array}$ \\
\hline
\end{tabular}




\section{Conflicts of Interest}

The authors declare no conflict of interest.

\section{References}

1. Van Schoor, N.M.; Lips, P. Worldwide Vitamin D Status. Best Pract. Res. Clin. Endocrinol. Metab. 2011, 25, 671-680.

2. Mithal, A.; Wahl, D.A.; Bonjour, J.P.; Burckhardt, P.; Dawson-Hughes, B.; Eisman, J.A.; El-Hajj Fuleihan, G.; Josse, R.G.; Lips, P.; Morales-Torres, J.; et al. Global vitamin D status and determinants of hypovitaminosis D. Osteoporos Int. 2009, 20, 1807-1820.

3. Van der Meer, I.M.; Middelkoop, B.J.; Boeke, A.J.; Lips, P. Prevalence of vitamin D deficiency among Turkish, Moroccan, Indian and sub-Sahara African populations in Europe and their countries of origin: An overview. Osteoporos. Int. 2011, 22, 1009-1021.

4. Hazell, T.J.; DeGuire, J.R.; Weiler, H.A. Vitamin D: An overview of its role in skeletal muscle physiology in children and adolescents. Nutr. Rev. 2012, 70, 520-533.

5. Holick, M.F. The role of vitamin D for bone health and fracture prevention. Curr. Osteoporos. Rep. 2006, 4, 96-102.

6. Lips, P.; van Schoor, N.M. The effect of vitamin D on bone and osteoporosis. Best Pract. Res. Clin. Endocrinol. Metab. 2011, 25, 585-591.

7. Janssen, H.C.; Samson, M.M.; Verhaar, H.J. Vitamin D deficiency, muscle function, and falls in elderly people. Am. J. Clin. Nutr. 2002, 75, 611-615.

8. Bischoff, H.A.; Stahelin, H.B.; Urscheler, N.; Ehrsam, R.; Vonthein, R.; Perrig-Chiello, P.; Tyndall, A.; Theiler, R. Muscle strength in the elderly: Its relation to vitamin D metabolites. Arch. Phys. Med. Rehabil. 1999, 80, 54-58.

9. Bischoff-Ferrari, H.A.; Dawson-Hughes, B.; Willett, W.C.; Staehelin, H.B.; Bazemore, M.G.; Zee, R.Y.; Wong, J.B. Effect of Vitamin D on falls: A meta-analysis. JAMA 2004, 291, 1999-2006.

10. Bischoff-Ferrari, H.A.; Dietrich, T.; Orav, E.J.; Dawson-Hughes, B. Positive association between 25-hydroxy vitamin D levels and bone mineral density: A population-based study of younger and older adults. Am. J. Med. 2004, 116, 634-639.

11. Bischoff-Ferrari, H.A.; Zhang, Y.; Kiel, D.P.; Felson, D.T. Positive association between serum 25-hydroxyvitamin D level and bone density in osteoarthritis. Arthritis Rheum. 2005, 53, $821-826$.

12. Thacher, T.D.; Clarke, B.L. Vitamin D insufficiency. Mayo Clin. Proc. 2011, 86, 50-60.

13. Murad, M.H.; Elamin, K.B.; Abu Elnour, N.O.; Elamin, M.B.; Alkatib, A.A.; Fatourechi, M.M.; Almandoz, J.P.; Mullan, R.J.; Lane, M.A.; Liu, H.; et al. Clinical review: The effect of vitamin D on falls: A systematic review and meta-analysis. J. Clin. Endocrinol. Metab. 2011, 96, 2997-3006.

14. Lips, P. Worldwide status of vitamin D nutrition. J. Steroid Biochem. Mol. Biol. 2010, 121, 297-300. 
15. Pilz, S.; Tomaschitz, A.; Marz, W.; Drechsler, C.; Ritz, E.; Zittermann, A.; Cavalier, E.; Pieber, T.R.; Lappe, J.M.; Grant, W.B.; et al. Vitamin D, cardiovascular disease and mortality. Clin. Endocrinol. 2011, 75, 575-584.

16. Haines, S.T.; Park, S.K. Vitamin D supplementation: What's known, what to do, and what's needed. Pharmacotherapy 2012, 32, 354-382.

17. Sisodia, R.S.; Jain, D.K.; Agarwal, S.S.; Gupta, A. TB control in India-Efforts, challenges and priorities. J. Indian Med. Assoc. 2011, 109, 921-924, 928.

18. Nnoaham, K.E.; Clarke, A. Low serum vitamin D levels and tuberculosis: A systematic review and meta-analysis. Int. J. Epidemiol. 2008, 37, 113-119.

19. Martineau, A.R. Old wine in new bottles: Vitamin D in the treatment and prevention of tuberculosis. Proc. Nutr. Soc. 2012, 71, 84-89.

20. Linday, L.A.; Shindledecker, R.D.; Dolitsky, J.N.; Chen, T.C.; Holick, M.F. Plasma 25-hydroxyvitamin D levels in young children undergoing placement of tympanostomy tubes. Ann. Otol. Rhinol. Laryngol. 2008, 117, 740-744.

21. Ginde, A.A.; Mansbach, J.M.; Camargo, C.A., Jr. Association between serum 25-hydroxyvitamin D level and upper respiratory tract infection in the Third National Health and Nutrition Examination Survey. Arch. Intern. Med. 2009, 169, 384-390.

22. Cannell, J.J.; Vieth, R.; Umhau, J.C.; Holick, M.F.; Grant, W.B.; Madronich, S.; Garland, C.F.; Giovannucci, E. Epidemic influenza and vitamin D. Epidemiol. Infect. 2006, 134, 1129-1140.

23. Wang, T.J.; Pencina, M.J.; Booth, S.L.; Jacques, P.F.; Ingelsson, E.; Lanier, K.; Benjamin, E.J.; D’Agostino, R.B.; Wolf, M.; Vasan, R.S. Vitamin D deficiency and risk of cardiovascular disease. Circulation 2008, 117, 503-511.

24. Ginde, A.A.; Scragg, R.; Schwartz, R.S.; Camargo, C.A., Jr. Prospective study of serum 25-hydroxyvitamin D level, cardiovascular disease mortality, and all-cause mortality in older U.S. adults. J. Am. Geriatr. Soc. 2009, 57, 1595-1603.

25. Rostand, S.G. Ultraviolet light may contribute to geographic and racial blood pressure differences. Hypertension 1997, 30, 150-156.

26. Martins, D.; Wolf, M.; Pan, D.; Zadshir, A.; Tareen, N.; Thadhani, R.; Felsenfeld, A.; Levine, B.; Mehrotra, R.; Norris, K. Prevalence of cardiovascular risk factors and the serum levels of 25-hydroxyvitamin D in the United States: Data from the Third National Health and Nutrition Examination Survey. Arch. Intern. Med. 2007, 167, 1159-1165.

27. Brewer, L.C.; Michos, E.D.; Reis, J.P. Vitamin D in atherosclerosis, vascular disease, and endothelial function. Curr. Drug Targets 2011, 12, 54-60.

28. Karvonen, M.; Viik-Kajander, M.; Moltchanova, E.; Libman, I.; LaPorte, R.; Tuomilehto, J. Incidence of childhood type 1 diabetes worldwide. Diabetes Mondiale (DiaMond) Project Group. Diabetes Care 2000, 23, 1516-1526.

29. Mohr, S.B.; Garland, C.F.; Gorham, E.D.; Garland, F.C. The association between ultraviolet B irradiance, vitamin D status and incidence rates of type 1 diabetes in 51 regions worldwide. Diabetologia 2008, 51, 1391-1398.

30. Hypponen, E.; Laara, E.; Reunanen, A.; Jarvelin, M.R.; Virtanen, S.M. Intake of vitamin D and risk of type 1 diabetes: A birth-cohort study. Lancet 2001, 358, 1500-1503. 
31. Zipitis, C.S.; Akobeng, A.K. Vitamin D supplementation in early childhood and risk of type 1 diabetes: A systematic review and meta-analysis. Arch. Dis. Child. 2008, 93, 512-517.

32. Modan, M.; Halkin, H.; Almog, S.; Lusky, A.; Eshkol, A.; Shefi, M.; Shitrit, A.; Fuchs, Z. Hyperinsulinemia. A link between hypertension obesity and glucose intolerance. J. Clin. Investig. 1985, 75, 809-817.

33. Dankner, R.; Chetrit, A.; Shanik, M.H.; Raz, I.; Roth, J. Basal-state hyperinsulinemia in healthy normoglycemic adults is predictive of type 2 diabetes over a 24-year follow-up: A preliminary report. Diabetes Care 2009, 32, 1464-1466.

34. Pittas, A.G.; Lau, J.; Hu, F.B.; Dawson-Hughes, B. The role of vitamin D and calcium in type 2 diabetes. A systematic review and meta-analysis. J. Clin. Endocrinol. Metab. 2007, 92, 2017-2029.

35. Garland, C.F.; Garland, F.C.; Gorham, E.D. Can colon cancer incidence and death rates be reduced with calcium and vitamin D? Am. J. Clin. Nutr. 1991, 54, 193S-201S.

36. Gorham, E.D.; Garland, C.F.; Garland, F.C.; Grant, W.B.; Mohr, S.B.; Lipkin, M.; Newmark, H.L.; Giovannucci, E.; Wei, M.; Holick, M.F. Optimal vitamin D status for colorectal cancer prevention: A quantitative meta analysis. Am. J. Prev. Med. 2007, 32, 210-216.

37. Hanchette, C.L.; Schwartz, G.G. Geographic patterns of prostate cancer mortality. Evidence for a protective effect of ultraviolet radiation. Cancer 1992, 70, 2861-2869.

38. Bischoff-Ferrari, H.A.; Giovannucci, E.; Willett, W.C.; Dietrich, T.; Dawson-Hughes, B. Estimation of optimal serum concentrations of 25-hydroxyvitamin D for multiple health outcomes. Am. J. Clin. Nutr. 2006, 84, 18-28.

39. Bertone-Johnson, E.R.; Chen, W.Y.; Holick, M.F.; Hollis, B.W.; Colditz, G.A.; Willett, W.C.; Hankinson, S.E. Plasma 25-hydroxyvitamin D and 1,25-dihydroxyvitamin D and risk of breast cancer. Cancer Epidemiol. Biomark. Prev. 2005, 14, 1991-1997.

40. Moan, J.; Porojnicu, A.C.; Dahlback, A.; Setlow, R.B. Addressing the health benefits and risks, involving vitamin D or skin cancer, of increased sun exposure. Proc. Natl. Acad. Sci. USA 2008, 105, 668-673.

41. Grant, W.B. Lower vitamin-D production from solar ultraviolet-B irradiance may explain some differences in cancer survival rates. J. Natl. Med. Assoc. 2006, 98, 357-364.

42. Garland, C.F.; Gorham, E.D.; Mohr, S.B.; Grant, W.B.; Giovannucci, E.L.; Lipkin, M.; Newmark, H.; Holick, M.F.; Garland, F.C. Vitamin D and prevention of breast cancer: Pooled analysis. J. Steroid Biochem. Mol. Biol. 2007, 103, 708-711.

43. Ahonen, M.H.; Tenkanen, L.; Teppo, L.; Hakama, M.; Tuohimaa, P. Prostate cancer risk and prediagnostic serum 25-hydroxyvitamin D levels (Finland). Cancer Causes Control 2000, 11, $847-852$.

44. Giovannucci, E.; Liu, Y.; Rimm, E.B.; Hollis, B.W.; Fuchs, C.S.; Stampfer, M.J.; Willett, W.C. Prospective study of predictors of vitamin D status and cancer incidence and mortality in men. J. Natl. Cancer Inst. 2006, 98, 451-459.

45. Lee, J.E.; Li, H.; Chan, A.T.; Hollis, B.W.; Lee, I.M.; Stampfer, M.J.; Wu, K.; Giovannucci, E.; Ma, J. Circulating levels of vitamin D and colon and rectal cancer: The Physicians' Health Study and a meta-analysis of prospective studies. Cancer Prev. Res. 2011, 4, 735-743. 
46. Holick, M.F.; Biancuzzo, R.M.; Chen, T.C.; Klein, E.K.; Young, A.; Bibuld, D.; Reitz, R.; Salameh, W.; Ameri, A.; Tannenbaum, A.D. Vitamin D2 is as effective as vitamin D3 in maintaining circulating concentrations of 25-hydroxyvitamin D. J. Clin. Endocrinol. Metab. 2008, 93, 677-681.

47. Biancuzzo, R.M.; Clarke, N.; Reitz, R.E.; Travison, T.G.; Holick, M.F. Serum concentrations of 1,25-dihydroxyvitamin D2 and 1,25-dihydroxyvitamin D3 in response to vitamin D2 and vitamin D3 supplementation. J. Clin. Endocrinol. Metab. 2013, 98, 973-979.

48. Thacher, T.D.; Obadofin, M.O.; O’Brien, K.O.; Abrams, S.A. The effect of vitamin D2 and vitamin D3 on intestinal calcium absorption in Nigerian children with rickets. J. Clin. Endocrinol. Metab. 2009, 94, 3314-3321.

49. Thacher, T.D.; Fischer, P.R.; Obadofin, M.O.; Levine, M.A.; Singh, R.J.; Pettifor, J.M. Comparison of metabolism of vitamins D2 and D3 in children with nutritional rickets. J. Bone Miner. Res. 2010, 25, 1988-1995.

50. Armas, L.A.; Hollis, B.W.; Heaney, R.P. Vitamin D2 is much less effective than vitamin D3 in humans. J. Clin. Endocrinol. Metab. 2004, 89, 5387-5391.

51. Trang, H.M.; Cole, D.E.; Rubin, L.A.; Pierratos, A.; Siu, S.; Vieth, R. Evidence that vitamin D3 increases serum 25-hydroxyvitamin D more efficiently than does vitamin D2. Am. J. Clin. Nutr. 1998, 68, 854-858.

52. Heaney, R.P.; Recker, R.R.; Grote, J.; Horst, R.L.; Armas, L.A. Vitamin D(3) is more potent than vitamin D(2) in humans. J. Clin. Endocrinol. Metab. 2011, 96, E447-E452.

53. Houghton, L.A.; Vieth, R. The case against ergocalciferol (vitamin D2) as a vitamin supplement. Am. J. Clin. Nutr. 2006, 84, 694-697.

54. Baidya, A.; Chowdhury, S.; Mukhopadhyay, S.; Ghosh, S. Profile of vitamin D in a cohort of physicians and diabetologists in Kolkata. Indian J. Endocrinol. Metab. 2012, 16, S416-S417.

55. Goswami, R.; Gupta, N.; Goswami, D.; Marwaha, R.K.; Tandon, N.; Kochupillai, N. Prevalence and significance of low 25-hydroxyvitamin D concentrations in healthy subjects in Delhi. Am. J. Clin. Nutr. 2000, 72, 472-475.

56. Tandon, N.; Marwaha, R.K.; Kalra, S.; Gupta, N.; Dudha, A.; Kochupillai, N. Bone mineral parameters in healthy young Indian adults with optimal vitamin D availability. Natl. Med. J. India 2003, 16, 298-302.

57. Marwaha, R.K.; Puri, S.; Tandon, N.; Dhir, S.; Agarwal, N.; Bhadra, K.; Saini, N. Effects of sports training \& nutrition on bone mineral density in young Indian healthy females. Indian J. Med. Res. 2011, 134, 307-313.

58. Multani, S.K.; Sarathi, V.; Shivane, V.; Bandgar, T.R.; Menon, P.S.; Shah, N.S. Study of bone mineral density in resident doctors working at a teaching hospital. J. Postgrad. Med. 2010, 56, 65-70.

59. Beloyartseva, M.; Mithal, A.; Kaur, P.; Kalra, S.; Baruah, M.P.; Mukhopadhyay, S.; Bantwal, G.; Bandgar, T.R. Widespread vitamin D deficiency among Indian health care professionals. Arch. Osteoporos. 2012, 7, 187-192.

60. Lo, C.W.; Paris, P.W.; Holick, M.F. Indian and Pakistani immigrants have the same capacity as Caucasians to produce vitamin D in response to ultraviolet irradiation. Am. J. Clin. Nutr. 1986, $44,683-685$. 
61. Clemens, T.L.; Adams, J.S.; Henderson, S.L.; Holick, M.F. Increased skin pigment reduces the capacity of skin to synthesise vitamin D3. Lancet 1982, 1, 74-76.

62. Matsuoka, L.Y.; Wortsman, J.; Haddad, J.G.; Kolm, P.; Hollis, B.W. Racial pigmentation and the cutaneous synthesis of vitamin D. Arch. Dermatol. 1991, 127, 536-538.

63. Agarwal, K.S.; Mughal, M.Z.; Upadhyay, P.; Berry, J.L.; Mawer, E.B.; Puliyel, J.M. The impact of atmospheric pollution on vitamin D status of infants and toddlers in Delhi, India. Arch. Dis. Child. 2002, 87, 111-113.

64. Jones, G.; Prosser, D.E.; Kaufmann, M.; Jones, G.; Prosser, D.E.; Kaufmann, M. 25-Hydroxyvitamin D-24-hydroxylase (CYP24A1): Its important role in the degradation of vitamin D. Arch. Biochem. Biophys. 2012, 523, 9-18.

65. Liao, E. FGF23 associated bone diseases. Front. Med. 2013, 7, 65-80.

66. Weaver, C.M.; Proulx, W.R.; Heaney, R. Choices for achieving adequate dietary calcium with a vegetarian diet. Am. J. Clin. Nutr. 1999, 70, 543S-548S.

67. Gupta, A. Osteoporosis in India-The nutritional hypothesis. Natl. Med. J. India 1996, 9, 268-274.

68. Caudarella, R.; Vescini, F.; Rizzoli, E.; Francucci, C.M. Salt intake, hypertension, and osteoporosis. J. Endocrinol. Investig. 2009, 32, 15-20.

69. Beaudoin, M.S.; Graham, T.E. Methylxanthines and human health: Epidemiological and experimental evidence. Handb. Exp. Pharmacol. 2011, 200, 509-548.

70. Tandon, R.K.; Joshi, Y.K.; Singh, D.S.; Narendranathan, M.; Balakrishnan, V.; Lal, K. Lactose intolerance in North and South Indians. Am. J. Clin. Nutr. 1981, 34, 943-946.

71. Babu, J.; Kumar, S.; Babu, P.; Prasad, J.H.; Ghoshal, U.C. Frequency of lactose malabsorption among healthy southern and northern Indian populations by genetic analysis and lactose hydrogen breath and tolerance tests. Am. J. Clin. Nutr. 2010, 91, 140-146.

72. Gallego Romero, I.; Basu Mallick, C.; Liebert, A.; Crivellaro, F.; Chaubey, G.; Itan, Y.; Metspalu, M.; Eaaswarkhanth, M.; Pitchappan, R.; Villems, R.; et al. Herders of Indian and European cattle share their predominant allele for lactase persistence. Mol. Biol. Evol. 2012, 29, 249-260.

73. Hollox, E.J.; Poulter, M.; Zvarik, M.; Ferak, V.; Krause, A.; Jenkins, T.; Saha, N.; Kozlov, A.I.; Swallow, D.M. Lactase haplotype diversity in the Old World. Am. J. Hum. Genet. 2001, 68, 160-172.

74. Harinarayan, C.V.; Ramalakshmi, T.; Venkataprasad, U. High prevalence of low dietary calcium and low vitamin D status in healthy south Indians. Asia Pac. J. Clin. Nutr. 2004, 13, 359-364.

75. Harinarayan, C.V.; Kochupillai, N.; Madhu, S.V.; Gupta, N.; Meunier, P.J. Fluorotoxic metabolic bone disease: An osteo-renal syndrome caused by excess fluoride ingestion in the tropics. Bone 2006, 39, 907-914.

76. Khandare, A.L.; Harikumar, R.; Sivakumar, B. Severe bone deformities in young children from vitamin D deficiency and fluorosis in Bihar-India. Calcif. Tissue Int. 2005, 76, 412-418.

77. Natri, A.M.; Salo, P.; Vikstedt, T.; Palssa, A.; Huttunen, M.; Karkkainen, M.U.; Salovaara, H.; Piironen, V.; Jakobsen, J.; Lamberg-Allardt, C.J. Bread fortified with cholecalciferol increases the serum 25-hydroxyvitamin D concentration in women as effectively as a cholecalciferol supplement. J. Nutr. 2006, 136, 123-127. 
78. Lu, Z.; Chen, T.C.; Zhang, A.; Persons, K.S.; Kohn, N.; Berkowitz, R.; Martinello, S.; Holick, M.F. An evaluation of the vitamin D3 content in fish: Is the vitamin D content adequate to satisfy the dietary requirement for vitamin D? J. Steroid Biochem. Mol. Biol. 2007, 103, 642-644.

79. Zargar, A.H.; Ahmad, S.; Masoodi, S.R.; Wani, A.I.; Bashir, M.I.; Laway, B.A.; Shah, Z.A. Vitamin D status in apparently healthy adults in Kashmir Valley of Indian subcontinent. Postgrad. Med. J. 2007, 83, 713-716.

80. Ramakrishnan, S.; Bhansali, A.; Bhadada, S.K.; Sharma, R.; Walia, R.; Ravikiran, M.; Shanmugasundar, G.; Ravikumar, P. Vitamin D status and its seasonal variability in healthy young adults in an Asian Indian urban population. Endocr. Pract. 2011, 17, 185-191.

81. Goswami, R.; Kochupillai, N.; Gupta, N.; Goswami, D.; Singh, N.; Dudha, A. Presence of $25(\mathrm{OH}) \mathrm{D}$ deficiency in a rural North Indian village despite abundant sunshine. J. Assoc. Physicians India 2008, 56, 755-757.

82. Goswami, R.; Marwaha, R.K.; Gupta, N.; Tandon, N.; Sreenivas, V.; Tomar, N.; Ray, D.; Kanwar, R.; Agarwal, R. Prevalence of vitamin D deficiency and its relationship with thyroid autoimmunity in Asian Indians: A community-based survey. Br. J. Nutr. 2009, 102, 382-386.

83. Vupputuri, M.R.; Goswami, R.; Gupta, N.; Ray, D.; Tandon, N.; Kumar, N. Prevalence and functional significance of 25-hydroxyvitamin D deficiency and vitamin D receptor gene polymorphisms in Asian Indians. Am. J. Clin. Nutr. 2006, 83, 1411-1419.

84. Puri, S.; Marwaha, R.K.; Agarwal, N.; Tandon, N.; Agarwal, R.; Grewal, K.; Reddy, D.H.; Singh, S. Vitamin D status of apparently healthy schoolgirls from two different socioeconomic strata in Delhi: Relation to nutrition and lifestyle. Br. J. Nutr. 2008, 99, 876-882.

85. Marwaha, R.K.; Tandon, N.; Reddy, D.R.; Aggarwal, R.; Singh, R.; Sawhney, R.C.; Saluja, B.; Ganie, M.A.; Singh, S. Vitamin D and bone mineral density status of healthy schoolchildren in northern India. Am. J. Clin. Nutr. 2005, 82, 477-482.

86. Marwaha, R.K.; Tandon, N.; Reddy, D.H.; Mani, K.; Puri, S.; Aggarwal, N.; Grewal, K.; Singh, S. Peripheral bone mineral density and its predictors in healthy school girls from two different socioeconomic groups in Delhi. Osteoporos. Int. 2007, 18, 375-383.

87. Marwaha, R.K.; Tandon, N.; Garg, M.K.; Kanwar, R.; Narang, A.; Sastry, A.; Saberwal, A.; Bandra, K. Vitamin D status in healthy Indians aged 50 years and above. J. Assoc. Physicians India 2011, 59, 706-709.

88. Garg, M.K.; Tandon, N.; Marwaha, R.K.; Menon, A.S.; Mahalle, N. The relationship between serum 25-hydroxy vitamin D, parathormone and bone mineral density in Indian population. Clin. Endocrinol. 2013, 80, 41-46.

89. Marwaha, R.K.; Tandon, N.; Chopra, S.; Agarwal, N.; Garg, M.K.; Sharma, B.; Kanwar, R.S.; Bhadra, K.; Singh, S.; Mani, K.; et al. Vitamin D status in pregnant Indian women across trimesters and different seasons and its correlation with neonatal serum 25-hydroxyvitamin D levels. Br. J. Nutr. 2011, 106, 1383-1389.

90. Seth, A.; Marwaha, R.K.; Singla, B.; Aneja, S.; Mehrotra, P.; Sastry, A.; Khurana, M.L.; Mani, K.; Sharma, B.; Tandon, N. Vitamin D nutritional status of exclusively breast fed infants and their mothers. J. Pediatr. Endocrinol. Metab. 2009, 22, 241-246. 
91. Tiwari, L.; Puliyel, J.M. Vitamin D level in slum children of Delhi. Indian Pediatr. 2004, 41, 1076-1077.

92. Mehrotra, P.; Marwaha, R.K.; Aneja, S.; Seth, A.; Singla, B.M.; Ashraf, G.; Sharma, B.; Sastry, A.; Tandon, N. Hypovitaminosis d and hypocalcemic seizures in infancy. Indian Pediatr. 2010, 47, 581-586.

93. Jain, V.; Gupta, N.; Kalaivani, M.; Jain, A.; Sinha, A.; Agarwal, R. Vitamin D deficiency in healthy breastfed term infants at 3 months \& their mothers in India: Seasonal variation \& determinants. Indian J. Med. Res. 2011, 133, 267-273.

94. Agarwal, R.; Virmani, D.; Jaipal, M.L.; Gupta, S.; Gupta, N.; Sankar, M.J.; Bhatia, S.; Agarwal, A.; Devgan, V.; Deorari, A.; et al. Vitamin D status of low birth weight infants in Delhi: A comparative study. J. Trop. Pediatr. 2012, 58, 446-450.

95. Agarwal, N.; Faridi, M.M.; Aggarwal, A.; Singh, O. Vitamin D Status of term exclusively breastfed infants and their mothers from India. Acta Paediatr. 2010, 99, 1671-1674.

96. Arya, V.; Bhambri, R.; Godbole, M.M.; Mithal, A. Vitamin D status and its relationship with bone mineral density in healthy Asian Indians. Osteoporos. Int. 2004, 15, 56-61.

97. Sachan, A.; Gupta, R.; Das, V.; Agarwal, A.; Awasthi, P.K.; Bhatia, V. High prevalence of vitamin D deficiency among pregnant women and their newborns in northern India. Am. J. Clin. Nutr. 2005, 81, 1060-1064.

98. Sahu, M.; Bhatia, V.; Aggarwal, A.; Rawat, V.; Saxena, P.; Pandey, A.; Das, V. Vitamin D deficiency in rural girls and pregnant women despite abundant sunshine in northern India. Clin. Endocrinol. 2009, 70, 680-684.

99. Agrawal, N.K.; Sharma, B. Prevalence of osteoporosis in otherwise healthy Indian males aged 50 years and above. Arch. Osteoporos. 2013, 8, 116.

100. Harinarayan, C.V.; Ramalakshmi, T.; Prasad, U.V.; Sudhakar, D. Vitamin D status in Andhra Pradesh: A population based study. Indian J. Med. Res. 2008, 127, 211-218.

101. Harinarayan, C.V. Prevalence of vitamin D insufficiency in postmenopausal south Indian women. Osteoporos. Int. 2005, 16, 397-402.

102. Paul, T.V.; Thomas, N.; Seshadri, M.S.; Oommen, R.; Jose, A.; Mahendri, N.V. Prevalence of osteoporosis in ambulatory postmenopausal women from a semiurban region in Southern India: Relationship to calcium nutrition and vitamin D status. Endocr. Pract. 2008, 14, 665-671.

103. Harinarayan, C.V.; Sachan, A.; Reddy, P.A.; Satish, K.M.; Prasad, U.V.; Srivani, P. Vitamin D status and bone mineral density in women of reproductive and postmenopausal age groups: A cross-sectional study from south India. J. Assoc. Physicians India 2011, 59, 698-704.

104. Farrant, H.J.; Krishnaveni, G.V.; Hill, J.C.; Boucher, B.J.; Fisher, D.J.; Noonan, K.; Osmond, C.; Veena, S.R.; Fall, C.H. Vitamin D insufficiency is common in Indian mothers but is not associated with gestational diabetes or variation in newborn size. Eur. J. Clin. Nutr. 2009, 63, 646-652.

105. Bhalala, U.; Desai, M.; Parekh, P.; Mokal, R.; Chheda, B. Subclinical hypovitaminosis D among exclusively breastfed young infants. Indian Pediatr. 2007, 44, 897-901.

106. Shivane, V.K.; Sarathi, V.; Bandgar, T.; Menon, P.; Shah, N.S. High prevalence of hypovitaminosis D in young healthy adults from the western part of India. Postgrad. Med. J. 2011, 87, 514-518. 
107. Ekbote, V.H.; Khadilkar, A.V.; Mughal, M.Z.; Hanumante, N.; Sanwalka, N.; Khadilkar, V.V.; Chiplonkar, S.A.; Kant, S.; Ganacharya, R. Sunlight exposure and development of rickets in Indian toddlers. Indian J. Pediatr. 2010, 77, 61-65.

108. Ekbote, V.H.; Khadilkar, A.V.; Chiplonkar, S.A.; Khadilkar, V.V. Determinants of bone mineral content and bone area in Indian preschool children. J. Bone Miner. Metab. 2011, 29, 334-341.

109. Khadilkar, A.; Crabtree, N.J.; Ward, K.A.; Khadilkar, V.; Shaw, N.J.; Mughal, M.Z. Bone status of adolescent girls in Pune (India) compared to age-matched South Asian and white Caucasian girls in the UK. Osteoporos. Int. 2010, 21, 1155-1160.

110. Kadam, N.; Chiplonkar, S.; Khadilkar, A.; Divate, U.; Khadilkar, V. Low bone mass in urban Indian women above 40 years of age: Prevalence and risk factors. Gynecol. Endocrinol. 2010, 26, 909-917.

111. Kadam, N.S.; Chiplonkar, S.A.; Khadilkar, A.V.; Fischer, P.R.; Hanumante, N.M.; Khadilkar, V.V. Modifiable factors associated with low bone mineral content in underprivileged premenarchal Indian girls. J. Pediatr. Endocrinol. Metab. 2011, 24, 975-981.

112. Marwaha, R.K.; Tandon, N.; Garg, M.K.; Kanwar, R.; Narang, A.; Sastry, A.; Saberwal, A.; Bhadra, K.; Mithal, A. Bone health in healthy Indian population aged 50 years and above. Osteoporos. Int. 2011, 22, 2829-2836.

113. Wang, T.J.; Zhang, F.; Richards, J.B.; Kestenbaum, B.; van Meurs, J.B.; Berry, D.; Kiel, D.P.; Streeten, E.A.; Ohlsson, C.; Koller, D.L.; et al. Common genetic determinants of vitamin D insufficiency: A genome-wide association study. Lancet 2010, 376, 180-188.

114. McCullough, M.L.; Bostick, R.M.; Mayo, T.L. Vitamin D gene pathway polymorphisms and risk of colorectal, breast, and prostate cancer. Annu. Rev. Nutr. 2009, 29, 111-132.

115. McGrath, J.J.; Saha, S.; Burne, T.H.; Eyles, D.W. A systematic review of the association between common single nucleotide polymorphisms and 25-hydroxyvitamin D concentrations. J. Steroid Biochem. Mol. Biol. 2010, 121, 471-477.

116. Hossein-nezhad, A.; Holick, M.F. Optimize dietary intake of vitamin D: An epigenetic perspective. Curr. Opin. Clin. Nutr. Metab. Care 2012, 15, 567-579.

117. Goswami, R.; Gupta, N.; Ray, D.; Singh, N.; Tomar, N. Pattern of 25-hydroxy vitamin D response at short (2 month) and long (1 year) interval after 8 weeks of oral supplementation with cholecalciferol in Asian Indians with chronic hypovitaminosis D. Br. J. Nutr. 2008, 100, 526-529.

118. Vieth, R. Why the minimum desirable serum 25-hydroxyvitamin D level should be $75 \mathrm{nmol} / \mathrm{L}$ (30 ng/mL). Best Pract. Res. Clin. Endocrinol. Metab. 2011, 25, 681-691.

119. Fulgoni, V.L., III; Keast, D.R.; Bailey, R.L.; Dwyer, J. Foods, fortificants, and supplements: Where do Americans get their nutrients? J. Nutr. 2011, 141, 1847-1854.

120. Langlois, K.; Greene-Finestone, L.; Little, J.; Hidiroglou, N.; Whiting, S. Vitamin D status of Canadians as measured in the 2007 to 2009 Canadian Health Measures Survey. Health Rep. 2010, 21, 47-55.

121. Calvo, M.S.; Whiting, S.J. Survey of current vitamin D food fortification practices in the United States and Canada. J. Steroid Biochem. Mol. Biol. 2013, 136, 211-213. 
122. Ekbote, V.H.; Khadilkar, A.V.; Chiplonkar, S.A.; Hanumante, N.M.; Khadilkar, V.V.; Mughal, M.Z. A pilot randomized controlled trial of oral calcium and vitamin D supplementation using fortified laddoos in underprivileged Indian toddlers. Eur. J. Clin. Nutr. 2011, 65, 440-446.

123. Khadgawat, R.; Marwaha, R.K.; Garg, M.K.; Ramot, R.; Oberoi, A.K.; Sreenivas, V.; Gahlot, M.; Mehan, N.; Mathur, P.; Gupta, N. Impact of vitamin D fortified milk supplementation on vitamin D status of healthy school children aged 10-14 years. Osteoporos. Int. 2013, 24, 2335-2343.

124. Sahu, M.; Das, V.; Aggarwal, A.; Rawat, V.; Saxena, P.; Bhatia, V. Vitamin D replacement in pregnant women in rural north India: A pilot study. Eur. J. Clin. Nutr. 2009, 63, 1157-1159.

125. Kalra, P.; Das, V.; Agarwal, A.; Kumar, M.; Ramesh, V.; Bhatia, E.; Gupta, S.; Singh, S.; Saxena, P.; Bhatia, V. Effect of vitamin D supplementation during pregnancy on neonatal mineral homeostasis and anthropometry of the newborn and infant. Br. J. Nutr. 2012, 108, 1052-1058.

126. Kumar, G.T.; Sachdev, H.S.; Chellani, H.; Rehman, A.M.; Singh, V.; Arora, H.; Filteau, S. Effect of weekly vitamin D supplements on mortality, morbidity, and growth of low birthweight term infants in India up to age 6 months: Randomised controlled trial. BMJ 2011, 342, d2975.

127. Trilok-Kumar, G.; Arora, H.; Rajput, M.; Chellani, H.; Singh, V.; Raynes, J.; Arya, S.; Aggarwal, S.; Srivastava, N.; Sachdev, H.P.; et al. Effect of vitamin D supplementation of low birth weight term Indian infants from birth on cytokine production at 6 months. Eur. J. Clin. Nutr. 2012, 66, 746-750.

128. Marwaha, R.K.; Tandon, N.; Agarwal, N.; Puri, S.; Agarwal, R.; Singh, S.; Mani, K. Impact of two regimens of vitamin D supplementation on calcium - vitamin D - PTH axis of schoolgirls of Delhi. Indian Pediatr. 2010, 47, 761-769.

129. Garg, M.K.; Marwaha, R.K.; Khadgawat, R.; Ramot, R.; Obroi, A.K.; Mehan, N.; Gupta, N.; Madan, R. Efficacy of vitamin D loading doses on serum 25-hydroxy vitamin D levels in school going adolescents: An open label non-randomized prospective trial. J. Pediatr. Endocrinol. Metab. 2013, 26, 515-523.

130. Goswami, R.; Vatsa, M.; Sreenivas, V.; Singh, U.; Gupta, N.; Lakshmy, R.; Aggarwal, S.; Ganapathy, A.; Joshi, P.; Bhatia, H. Skeletal muscle strength in young Asian Indian females after vitamin D and calcium supplementation: A double-blind randomized controlled clinical trial. J. Clin. Endocrinol. Metab. 2012, 97, 4709-4716.

131. Gupta, R.; Sharma, U.; Gupta, N.; Kalaivani, M.; Singh, U.; Guleria, R.; Jagannathan, N.R.; Goswami, R. Effect of cholecalciferol and calcium supplementation on muscle strength and energy metabolism in vitamin D-deficient Asian Indians: A randomized, controlled trial. Clin. Endocrinol. 2010, 73, 445-451.

132. Agarwal, N.; Mithal, A.; Dhingra, V.; Kaur, P.; Godbole, M.M.; Shukla, M. Effect of two different doses of oral cholecalciferol supplementation on serum 25-hydroxy-vitamin D levels in healthy Indian postmenopausal women: A randomized controlled trial. Indian J. Endocrinol. Metab. 2013, 17, 883-889.

133. Khadilkar, A.V.; Sayyad, M.G.; Sanwalka, N.J.; Bhandari, D.R.; Naik, S.; Khadilkar, V.V.; Mughal, M.Z. Vitamin D supplementation and bone mass accrual in underprivileged adolescent Indian girls. Asia Pac. J. Clin. Nutr. 2010, 19, 465-472. 
134. Khadilkar, A.; Kadam, N.; Chiplonkar, S.; Fischer, P.R.; Khadilkar, V. School-based calcium-vitamin D with micronutrient supplementation enhances bone mass in underprivileged Indian premenarchal girls. Bone 2012, 51, 1-7.

135. Nordin, B.E. International patterns of osteoporosis. Clin. Orthop. Relat. Res. 1966, 45, 17-30.

136. Malhotra, N.; Mithal, A. Osteoporosis in Indians. Indian J. Med. Res. 2008, 127, 263-268.

137. SP, S.T.; Teotia, M. Nutritional bone disease in Indian population. Indian J. Med. Res. 2008, 127, 219-228.

138. Lowe, N.M.; Ellahi, B.; Bano, Q.; Bangash, S.A.; Mitra, S.R.; Zaman, M. Dietary calcium intake, vitamin D status, and bone health in postmenopausal women in rural Pakistan. J. Health Popul. Nutr. 2011, 29, 465-470.

139. Rashid, A.; Mohammed, T.; Stephens, W.P.; Warrington, S.; Berry, J.L.; Mawer, E.B. Vitamin D state of Asians living in Pakistan. Br. Med. J. 1983, 286, 182-184.

140. Mansoor, S.; Habib, A.; Ghani, F.; Fatmi, Z.; Badruddin, S.; Mansoor, S.; Siddiqui, I.; Jabbar, A. Prevalence and significance of vitamin D deficiency and insufficiency among apparently healthy adults. Clin. Biochem. 2010, 43, 1431-1435.

141. Khan, A.H.; Iqbal, R.; Naureen, G.; Dar, F.J.; Ahmed, F.N. Prevalence of vitamin D deficiency and its correlates: Results of a community-based study conducted in Karachi, Pakistan. Arch. Osteoporos. 2012, 7, 275-282.

142. Karim, S.A.; Nusrat, U.; Aziz, S. Vitamin D deficiency in pregnant women and their newborns as seen at a tertiary-care center in Karachi, Pakistan. Int. J. Gynaecol. Obstet. 2011, 112, 59-62.

143. Hossain, N.; Khanani, R.; Hussain-Kanani, F.; Shah, T.; Arif, S.; Pal, L. High prevalence of vitamin D deficiency in Pakistani mothers and their newborns. Int. J. Gynaecol. Obstet. 2011, 112, 229-233.

144. Atiq, M.; Suria, A.; Nizami, S.Q.; Ahmed, I. Vitamin D status of breastfed Pakistani infants. Acta Paediatr. 1998, 87, 737-740.

145. Islam, M.Z.; Lamberg-Allardt, C.; Karkkainen, M.; Outila, T.; Salamatullah, Q.; Shamim, A.A. D deficiency: A concern in premenopausal Bangladeshi women of two socio-economic groups in rural and urban region. Eur. J. Clin. Nutr. 2002, 56, 51-56.

146. Islam, M.Z.; Akhtaruzzaman, M.; Lamberg-Allardt, C. Hypovitaminosis D is common in both veiled and nonveiled Bangladeshi women. Asia Pac. J. Clin. Nutr. 2006, 15, 81-87.

147. Islam, M.Z.; Shamim, A.A.; Kemi, V.; Nevanlinna, A.; Akhtaruzzaman, M.; Laaksonen, M.; Jehan, A.H.; Jahan, K.; Khan, H.U.; Lamberg-Allardt, C. Vitamin D deficiency and low bone status in adult female garment factory workers in Bangladesh. Br. J. Nutr. 2008, 99, 1322-1329.

148. Roth, D.E.; Shah, M.R.; Black, R.E.; Baqui, A.H. Vitamin D status of infants in northeastern rural Bangladesh: Preliminary observations and a review of potential determinants. J. Health Popul. Nutr. 2010, 28, 458-469.

149. Doi, M.; Rekha, R.S.; Ahmed, S.; Okada, M.; Roy, A.K.; El Arifeen, S.; Ekstrom, E.C.; Raqib, R.; Wagatsuma, Y. Association between calcium in cord blood and newborn size in Bangladesh. Br. J. Nutr. 2011, 106, 1398-1407.

150. Ullah, M.I.; Koch, C.A.; Tamanna, S.; Rouf, S.; Shamsuddin, L. Vitamin D deficiency and the risk of preeclampsia and eclampsia in Bangladesh. Horm. Metab. Res. 2013, 45, 682-687. 
151. Jiang, T.; Christian, P.; Khatry, S.K.; Wu, L.; West, K.P., Jr. Micronutrient deficiencies in early pregnancy are common, concurrent, and vary by season among rural Nepali pregnant women. J. Nutr. 2005, 135, 1106-1112.

152. Meyer, H.E.; Holvik, K.; Lofthus, C.M.; Tennakoon, S.U. Vitamin D status in Sri Lankans living in Sri Lanka and Norway. Br. J. Nutr. 2008, 99, 941-944.

153. Hettiarachchi, M.; Liyanage, C. Coexisting micronutrient deficiencies among Sri Lankan pre-school children: A community-based study. Matern. Child Nutr. 2012, 8, 259-266.

154. Roth, D.E.; Al Mahmud, A.; Raqib, R.; Akhtar, E.; Perumal, N.; Pezzack, B.; Baqui, A.H., Randomized placebo-controlled trial of high-dose prenatal third-trimester vitamin D3 supplementation in Bangladesh: The AViDD trial. Nutr. J. 2013, 12, 47.

155. Ali, B.; Butt, A.; Fatima, A.; McDonnell, M.E.; Masud, F. Tibial tenderness identifies secondary hyperparathyroidism responding to high-dose vitamin d in pakistani women. Endocr. Pract. 2013, 19, 596-601.

(C) 2014 by the authors; licensee MDPI, Basel, Switzerland. This article is an open access article distributed under the terms and conditions of the Creative Commons Attribution license (http://creativecommons.org/licenses/by/3.0/). 